\title{
POLÍTICAS FISCALES PARA MEJORAR EL ACCESO ECONÓMICO A DIETAS SALUDABLES
}

Eugenio Díaz-Bonilla, Miriam Centurión, y Florencia Paz 


\section{CONTENIDOS}

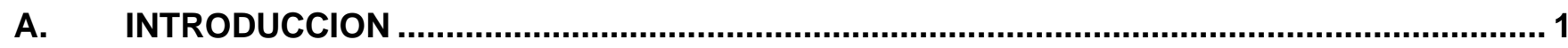

B. MARCO CONCEPTUAL

C. IMPUESTOS INTERNOS A LA PRODUCCIÓN DE ALIMENTOS NO SALUDABLES. ............. 6

D. IMPUESTOS INTERNOS AL CONSUMO DE ALIMENTOS NO SALUDABLES........................ 6

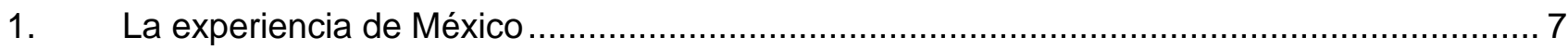

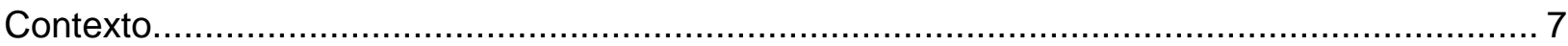

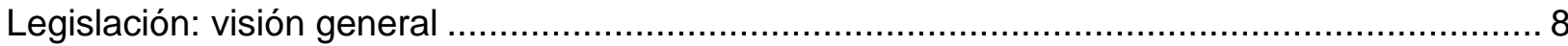

Evaluaciones del impuesto sobre las bebidas azucaradas ................................................... 9

Evaluaciones del impuesto a la comida no esencial con alto contenido calórico ....................... 10

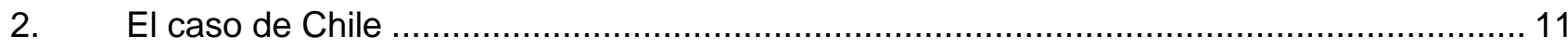

3. Impuestos a las Bebidas Alcohólicas ........................................................................... 14

E. SUBSIDIOS Y EXENCIONES IMPOSITIVAS AL CONSUMO DE ALIMENTOS SALUDABLES 16

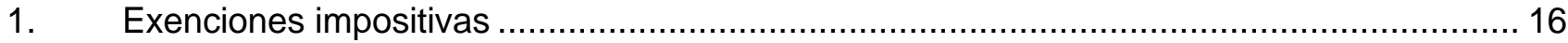

2. Otras modalidades de ventas a precios subsidiados y/o distribución gratuita de alimentos 17

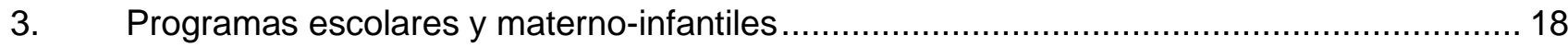

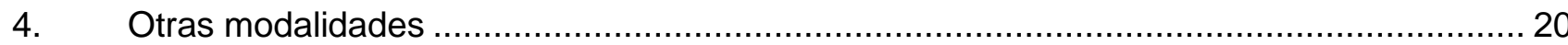

F. COMBINACIÓN DE IMPUESTOS AL CONSUMO DE ALIMENTOS NO SALUDABLES Y

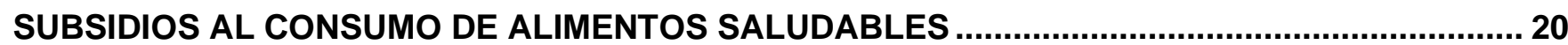

G. SUBSIDIOS Y EXENCIONES IMPOSITIVAS A LA PRODUCCIÓN DE ALIMENTOS ............. 21

H. IMPUESTOS O SUBSIDIOS RELACIONADOS CON EL TRANSPORTE O LA VENTA MINORISTA DE PRODUCTOS ALIMENTICIOS SALUDABLES O NO SALUDABLES....................... 26

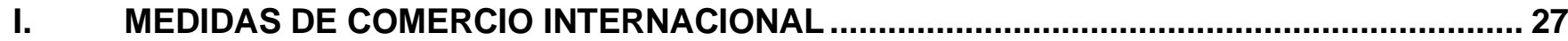

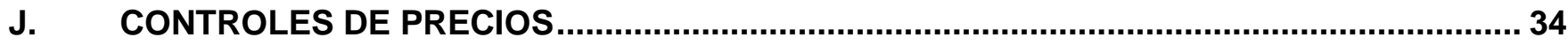

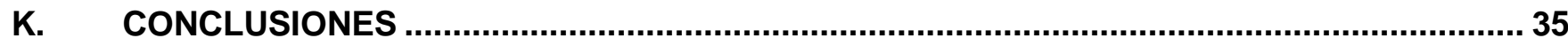

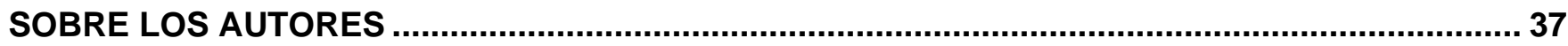

AGRADECIMIENTOS ........................................................................ Error! Bookmark not defined.

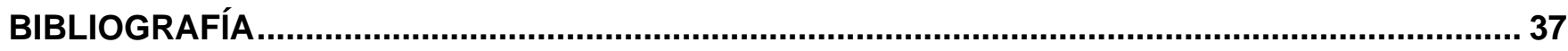




\section{CUADROS}

Cuadro 1: Diferentes Políticas Relacionadas con las Dietas Saludables ....................................... 4

Cuadro 2: Ejemplos de Impuestos al Consumo en ALC ............................................................. 7

Cuadro 3: Impuestos a las Bebidas Alcohólicas ..................................................................... 15

Cuadro 4: Transferencias a los Productores de Contribuyentes como porcentaje del valor de Producción.

\section{GRÁFICOS}

Gráfico 1: Factores y efectos de la Malnutrición ................................................................... 3

Gráfico 2: Impuestos y Subsidios a la Producción ..................................................................... 5

Gráfico 3: Bebidas Alcohólicas (kcal/cápita/dia) ...................................................................... 14

Gráfico 4: Impuestos a las Importaciones ........................................................................... 27

Gráfico 5: Impuesto a las Exportaciones ............................................................................. 28

Gráfico 6: Coeficiente de Protección Nominal........................................................................ 30

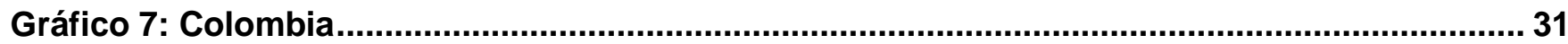

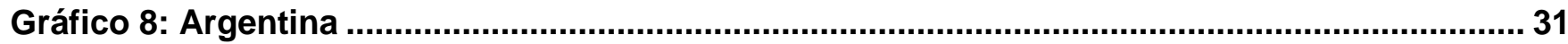

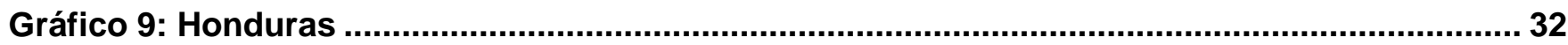

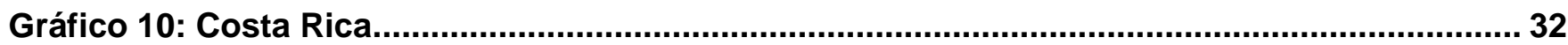

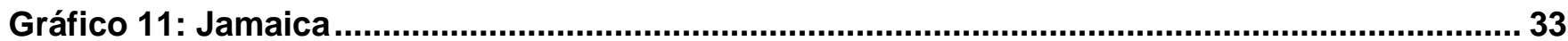




\section{A. INTRODUCCION}

Este es un documento de apoyo a la Consulta Regional en "Innovaciones en políticas económicas y sociales para hacer frente a el sobrepeso y la obesidad en América Latina y el Caribe," organizada por la FAO con apoyo del IFPRI.

El foco particular es el acceso económico de toda la población para acceder a una alimentación suficiente, saludable y diversificada, con el objetivo de mejorar las condiciones de pobreza, hambre, malnutrición y las enfermedades y muertes asociadas con dietas inadecuadas.

El acceso económico a dietas saludables depende especialmente de los precios de los productos y de los ingresos de los consumidores, pero también presupone la disponibilidad y accesibilidad física, y la conveniencia de la dieta. Se puede plantear que los aspectos de disponibilidad y accesibilidad, por una parte, y los de conveniencia, por el otro, afectan el "precio efectivo total" de la dieta: el precio de compra directo de los productos que componen la dieta, más los costos de transporte y tiempo de llegar al lugar donde están disponibles para su compra, más los costos de tiempo y preparación de esos productos en la dieta que finalmente se consume.

Por ende, desde esta perspectiva, se deberían analizar todas las políticas que incidan en esas variables. Este documento se centra en un conjunto más acotado de esas políticas (como se discute más adelante). Por otra parte, existen otras importantes medidas para mejorar las dietas, como, por ejemplo, las relacionadas con etiquetado, publicidad, información y educación; pero no inciden directamente sobre el acceso económico tal como fue caracterizado más arriba. En las siguientes secciones se presenta primero un breve marco conceptual para categorizar las políticas, y se explica el tipo o tipos de políticas discutidos en este documento, ${ }^{1}$ con un foco en América Latina y el Caribe (ALC). Finalmente se presentan algunas conclusiones preliminares de política.

\footnotetext{
1: Biermayr-Jenzano (2020) es la publicación complementaria donde se cubre el análisis de las políticas de acceso económico basadas en mejoras de los ingresos y provisión directa de alimentos.
} 


\section{MARCO CONCEPTUAL ${ }^{2}$}

En el análisis de políticas públicas (basado en la economía del bienestar), las intervenciones de los gobiernos se justifican, por una parte, por la existencia de fallas de mercado que provoca ineficiencias económicas o, por otra parte, debido a motivos de equidad. Este segundo motivo es diferente e independiente del criterio de eficiencia (relacionada con fallas de mercado). Una tercera consideración a tener en cuenta en las políticas públicas es la presencia de "fallas de gobierno:" la posibilidad que, aunque haya fallas de mercado o problemas de equidad, el sector público, cuando interviene, pueda implementar políticas que, por diferentes razones, no resuelven el problema que se intenta corregir, y hasta pueden agravarlo, o generar otros resultados indeseados.

Una falla del mercado bien conocida es la presencia de externalidades generadas por las decisiones de producción o consumo por parte de productores o consumidores, lo que genera efectos (positivos o negativos) en otros, pero que no están siendo internalizados por aquéllos que los generan. En el caso de las externalidades negativas, habrá un exceso de producción o consumo del bien o servicio que las genera (de manera opuesta, en el caso de externalidades positiva habrá menos producción o consumo de lo que sería socialmente deseable).

La recomendación normativa habitual en el caso de las externalidades negativas es usar instrumentos de políticas basados en precios (como impuestos) o instrumentos cuantitativos (como prohibiciones y regulaciones) de modo que estas externalidades se reduzcan o eliminen. En el caso de las externalidades positivas, los instrumentos pueden ser subsidios u otras políticas que expandan la cantidad de los productos que las generan (por ejemplo, la producción por parte del sector público del bien o servicio que genera las externalidades).

Si el problema es uno de equidad (en este caso, el hecho que algunos grupos no tienen acceso económico a dietas saludables, lo que les negaría un derecho básico), entonces las políticas pueden ser de rebajas de precios efectivos, transferencias de ingresos monetarios, y/o medidas cuantitativas (por ejemplo, cajas de alimentos, o la provisión de almuerzos escolares a alumnos pobres).

El sistema alimentario puede generar diferentes tipos de externalidades, positivas y negativas, incluidos aspectos relacionados con el medio ambiente y la salud. En particular, los costos de la mala nutrición en términos de gastos de salud privados y públicos y la reducción general de la productividad económica son externalidades negativas no triviales para las sociedades. Esa malnutrición tiene al menos tres manifestaciones (las llamadas tres "cargas de malnutrición"): 1) desnutrición (falta de calorías, o hambre); 2) falta de minerales, vitaminas y otros nutrientes esenciales (lo que se ha llamado "hambre oculta"); y 3) sobrepeso y obesidad (con su correlato de enfermedades no transmisibles, ENT). Por lo tanto, habría razones para pensar en políticas públicas que alineen las externalidades de manera de aumentar el bienestar de la sociedad.

Para definir las políticas e intervenciones adecuadas, es necesario responder varias preguntas en secuencia. La primera es cuál es la externalidad: en este caso serían los resultados de salud y productividad (positivos o negativos). La segunda, es dónde se origina esa externalidad: de la dieta o por otras razones (por ejemplo, quizás la falta de ejercicio).

\footnotetext{
${ }^{2}$ Esta sección se basa en el documento de trabajo de Diaz-Bonilla et al. (2018) basado en el foro sobre los sistemas alimentarios y la obesidad en América Latina y el Caribe.
} 
Si el foco es la dieta, entonces una tercera pregunta es quién es responsable de ese consumo de dietas no saludable: ¿las empresas de alimentos (que producen y promueven productos poco saludables a través de intensas campañas de publicidad y agresivas estrategias de mercadotecnia)?; ¿० es un problema de los consumidores (que no se informan; miran solamente los precios más bajos y la conveniencia, pero no las características nutritivas de los productos; que no hacen suficiente ejercicio; y que comen demasiado de todo)?

Luego se abren varios niveles de análisis para determinar los puntos de intervención, como se analiza más abajo.

Hasta acá se discutió la falla de mercado (externalidades). Pero como se dijo, puede haber razones de equidad: los seres humanos tienen derecho a una alimentación saludable, y si esto no está sucediendo en el caso de ciertos grupos de personas pobres y vulnerables, entonces los gobiernos pueden intervenir para asegurar ese acceso para las personas afectadas. Pero, aunque no es la razón principal para una política pública que se basa en razones de equidad, el hecho que las personas carenciadas puedan tener acceso a dietas saludables también tiene externalidades positivas para el resto de la sociedad: habría menos costos de salud, y una mayor productividad.

En todo caso, con ambas perspectivas (eficiencia y equidad), la variable de interés en este trabajo es la dieta saludable, pero reconociendo que hay otros factores que contribuyen a los problemas de malnutrición, como se muestra en el Gráfico 1.

\section{Gráfico 1: Factores y efectos de la Malnutrición}

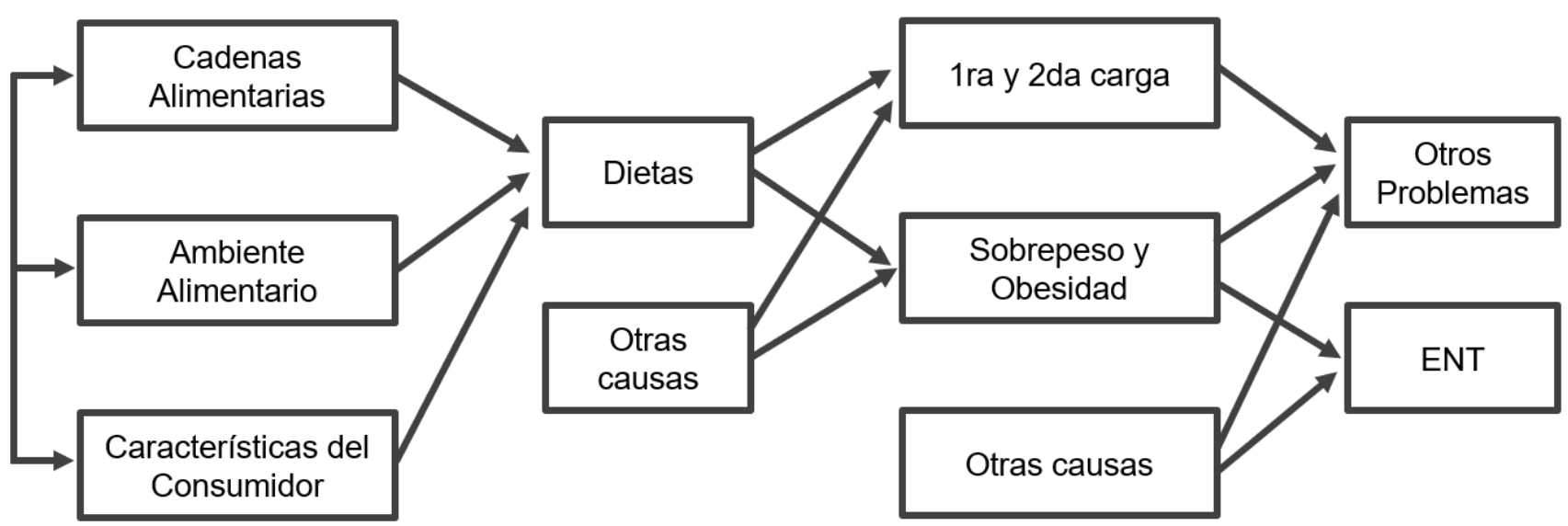

Fuente: Autores. ENT: enfermedades no transmisibles

Dentro de la discusión de dietas saludables hay también al menos dos aspectos: uno es si el problema es la cantidad (en el caso de la desnutrición el bajo nivel de consumo de calorías; y en el caso de sobrepeso y obesidad el exceso de consumo de las mismas, con porciones alimentarias de gran tamaño, quizás como resultado de la publicidad y promoción que crea y expande la demanda); o si se trata de la poco saludable composición nutricional de las dietas actuales (al diseñar productos que tienen muy buen sabor, incluso son adictivos, con un exceso de azúcar, sal y grasas inadecuadas y falta de vitaminas, minerales y otros nutrientes esenciales). 
Este último punto lleva a la discusión, no de la totalidad de la dieta en general, sino de productos específicos (como por ejemplo las bebidas azucaradas o productos de comida rápida) o aún de ingredientes por separado (como el azúcar y la sal).

Finalmente, está el tema de los instrumentos de políticas para mejorar la producción y consumo de dietas saludables. El Cuadro 1 tiene algunos ejemplos que sirven para luego definir el foco de este documento (una discusión más detallada de diferentes marcos para clasificar políticas puede verse en Diaz-Bonilla, Eugenio; Paz, Flor; and Biermayr-Jenzano, Patricia. 2020).

\section{Cuadro 1: Diferentes Políticas Relacionadas con las Dietas Saludables}

PRODUCTORES Y COMERCIANTES

I. Precios (impuestos, subsidios y exenciones impositivas)

III. Producción y comercio (gasto público en infraestructura, ciencia y tecnología y otros; comercio internacional)

V. Cantidad y composición de productos (regulaciones, prohibiciones de producción)

VII. Ambiente alimentario por el lado de la producción y comercialización (regulaciones, restricciones, prohibiciones de venta de ciertos productos, en ciertos espacios, o a ciertos consumidores)

\section{CONSUMIDORES}

II. Precios (impuestos, subsidios y exenciones impositivas)

IV. Ingresos y acceso físico directo (apoyos monetarios, tarjetas alimentarias, cajas de alimentos, comedores escolares y otros)

VI. Preferencias del consumidor (Guías alimentarias, etiquetado, educación, y otros)

VIII. Ambiente alimentario por el lado del consumidor (regulaciones e inversiones para mejorar la densidad de puntos de venta de alimentos saludables)

Fuente: Autores

El cuadro anterior sugiere que hay muchas medidas que pueden llevar a la producción y consumo de dietas saludables. Este trabajo se centra en algunas de las medidas del Cuadro 1: básicamente las que se relacionan con los cuadrantes I), II) y parte de III):

1. impuestos o subsidios de carácter universal o focalizado que faciliten la producción, procesamiento, distribución, comercialización o venta de alimentos que contribuyan a dietas saludables (cuadrante I)

2. Impuestos o subsidios de carácter universal o focalizado que faciliten el consumo de alimentos que contribuyan a dietas saludables (cuadrante II).

3. Políticas de comercio internacional con efectos comparables (tales como impuestos o subsidios al comercio internacional) (parte del cuadrante III).

4. Otras posibles políticas fiscales o relacionadas que promuevan el acceso a dietas saludables (por ejemplo, rebajas de impuestos) (que entrarían en los cuadrantes I y II).

En un documento separado se analizan los temas mencionados en el cuadrante IV. Los bloques de políticas en los otros cuadrantes, ciertamente, muy importantes, no son parte de esta revisión. 
Obviamente, un impuesto a la producción (A en el Gráfico 2) reduce la cantidad producida y, por ende, la consumida: en este ejemplo sin comercio internacional baja de Q1 a Q2, en el primer panel. Por su parte, un subsidio (B en el Gráfico 2) tiene el resultado opuesto: incrementa la cantidad producida y consumida de Q1 a Q2, en el segundo panel. Hay otros resultados, llamados de equilibrio general que también hay que considerar ya que lo que pasa en el mercado del producto afectado por un subsidio o un impuesto puede tener repercusiones en otros mercados.

\section{Gráfico 2: Impuestos y Subsidios a la Producción}
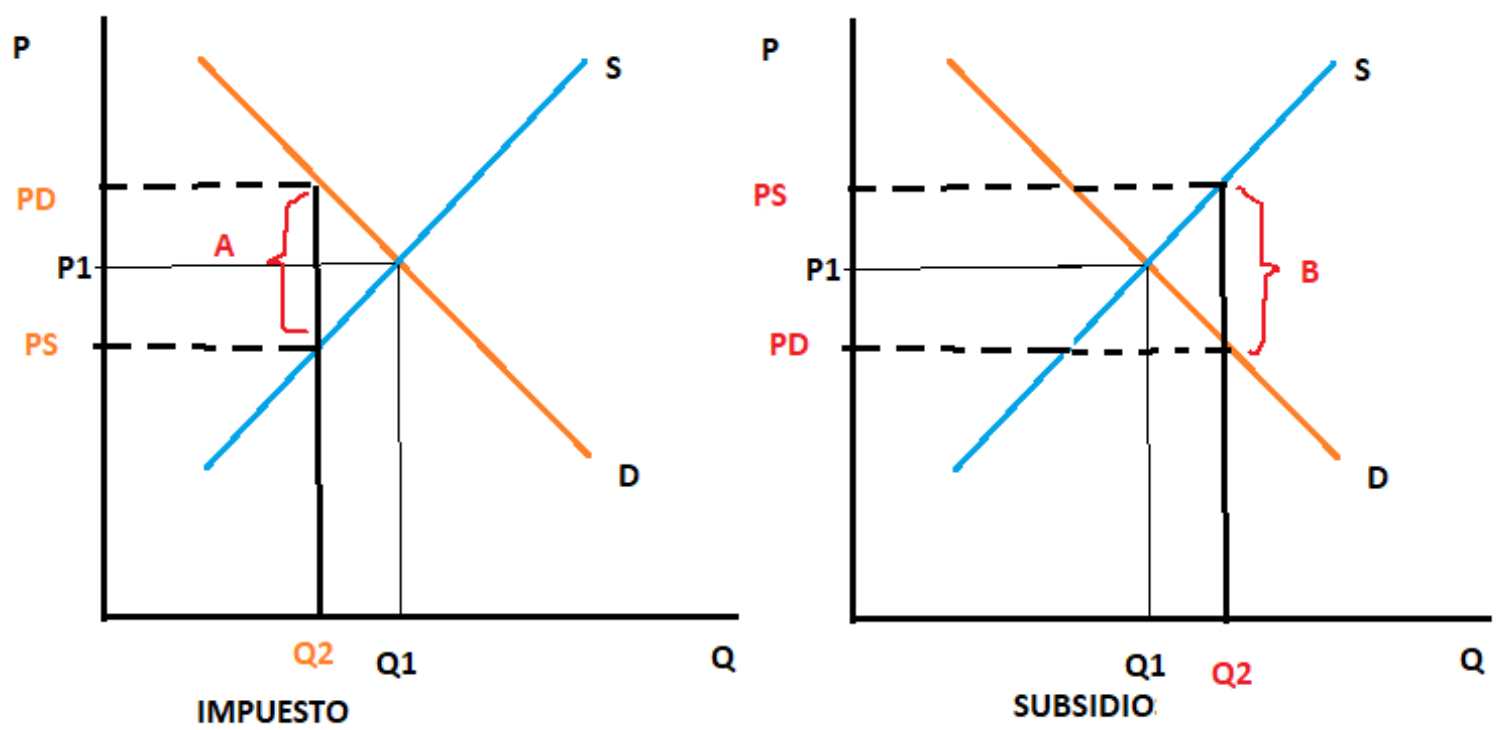

Fuente: Autores

Estos gráficos se refieren a la producción nacional. Un análisis separado se hace más adelante para productos con comercio internacional.

Usando el ejemplo simplificado de el Gráfico 2, también puede verse el impacto de un impuesto o un subsidio al consumo, con resultados gráficos similares. ${ }^{3} \mathrm{El}$ impuesto baja la producción consumida de Q1 a Q2 (en el primer panel), mientras que el subsidio la aumenta de Q1 a Q2 (en el segundo panel).

Los cambios en el consumo también generan cambios en la producción, lo que a su vez puede generar efectos de segunda vuelta en otras actividades.

Existen diferentes tipos de impuestos. ${ }^{4}$ Los impuestos aplicados a un producto en particular en el punto de fabricación son llamados impuestos especiales ("excise tax" en inglés). Estos pueden ser a) específicos, y, a su vez, puede estar basado en el volumen/cantidad total del producto, o en el contenido de los componentes que se quieren limitar (por ejemplo, azúcar, grasas, sal, o calorías); o pueden ser b) ad valorem (calculado sobre un porcentaje del precio mayorista o minorista). A su vez, los impuestos que consideran el contenido de los componentes que se quieren limitar pueden aplicarse a

\footnotetext{
${ }^{3}$ Ciertamente, la tasa de impuesto o del subsidio medida en porcentajes es diferente, porque en un caso la base imponible es el precio del productor y en el otro es el precio al consumidor. Acá se está usando simplemente un ejemplo en el que la barra A (representando el impuesto) y la barra B (representando el subsidio) son iguales en valor (pero no como porcentaje del precio de referencia).

${ }^{4}$ Ver por ejemplo, https://www.obesityevidencehub.org.au/collections/prevention/countries-that-have-implemented-taxes-on-sugar-sweetened-beverages-ssbs
} 
partir de un cierto límite (por ejemplo, por encima de "X gramos") o ser escalonados, con diferentes tasas de impuestos que van subiendo según el contenido de las substancias que se quieren limitar en la producción y el consumo.

En el punto de uso o consumo se usa el impuesto a las ventas (que se aplica al valor total del producto cada vez que se lo vende), o el impuesto al valor agregado (un impuesto al consumo aplicado a un producto cada vez que se agrega valor en cada etapa de la cadena de suministro, desde la producción hasta el punto de venta).

A continuación, se van a analizar diferentes políticas relacionadas con los aspectos económicos de dietas saludables. El análisis considera especialmente los siguientes países para ejemplificar las posibles intervenciones para ejemplificar las posibles intervenciones: Argentina, Brasil, Chile, Colombia, Costa Rica, Honduras, Jamaica y México.

\section{IMPUESTOS INTERNOS A LA PRODUCCIÓN DE ALIMENTOS NO SALUDABLES.}

Ninguno de los países analizados tiene impuestos internos a la producción de alimentos no saludables. Diferente es el tema de impuestos relacionados con el comercio internacional, lo cual incide en el precio interno de una variedad de productos, saludables y no saludables. Estos aspectos se discuten más adelante.

\section{IMPUESTOS INTERNOS AL CONSUMO DE ALIMENTOS NO SALUDABLES}

Esta sección analiza algunas políticas impositivas internas (para diferenciarlas de las políticas de comercio internacional, que se discuten más adelante) que suben directamente el precio que paga el consumidor por los alimentos para desalentar su consumo (aunque como se muestra en el Gráfico 2 , estas medidas también pueden cambiar los precios al productor).

El Cuadro 2 muestra algunos ejemplos de los países considerados, antes de entrar en detalle en los dos países que tienen más experiencia en el uso de impuestos para promover dietas saludables, México y Chile. 


\section{Cuadro 2: Ejemplos de Impuestos al Consumo en ALC}

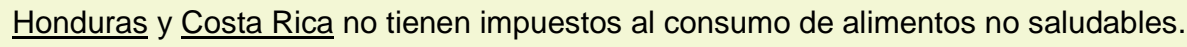

Jamaica tenía un impuesto específico al consumo ad valorem de $15 \%$ sobre bebidas no alcohólicas con alto contenido de cafeína (energy drinks) desde diciembre de 2010, pero esta fue retirada en $2011 .^{5}$

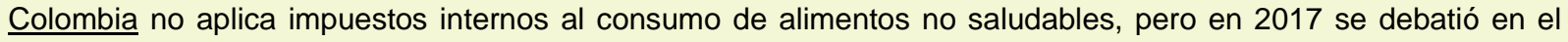
congreso una ley para aplicar un impuesto del $20 \%$ sobre bebidas azucaradas, que finalmente fue rechazada.

Argentina aplica un impuesto a las bebidas sin alcohol que varía en un rango de $4 \%$ a $8 \%$. En el año 2017 el gobierno propuso un incremento al 17\%, pero el Congreso rechazó la propuesta y se mantuvieron las alícuotas vigentes. ${ }^{6}$

Brasil tiene el impuesto sobre productos industrializados (IPI) con una alícuota de 4\% sobre aguas minerales y gasificadas con contenido de azúcar y otros edulcorantes. Aguas minerales y gasificadas con aromatizantes tienen una alícuota de $2 \%$. Brasil aplica un crédito fiscal sobre el IPI que pagan las bebidas gaseosas como Coca Cola y Pepsi, cuando las empresas productoras se encuentran localizadas en la zona de libre comercio de Manaos, pero no las que producen en el resto del país. ${ }^{7}$ En 2019 se incrementó el crédito del $8 \%$ al $10 \%$ de lo que se pague de IPI. Por ende, al menos para las empresas en las zonas francas, se puede argumentar que el crédito fiscal es una forma de subsidio a esas bebidas.

Fuente: autores sobre la base de información recopilada

\section{La experiencia de México}

\section{Contexto}

México es probablemente el país de la región con mayor experiencia en el uso de impuestos para desalentar el consumo de alimentos no saludables. Esto se debe a que también sufre uno de los niveles de sobrepeso y obesidad más altos del mundo, lo que tiene como correlato una alta incidencia de diabetes, problemas cardiovasculares y otras enfermedades no transmisibles.

Según algunas estimaciones que fueron utilizadas como antecedentes para aprobar los impuestos discutidos más abajo, el costo total del sobrepeso y la obesidad (directo e indirecto) se duplicó entre 2000 y 2008, de MXN 35,429 millones (alrededor de US\$ 2,615 millones) a MXN 67,345 millones (US\$ 4,970 millones), y proyectaban, que si no se tomaban medidas, el costo iba a llegar a MXN 73,000 millones (US\$ 5,387 millones) (PAHO, 2015). ${ }^{8}$

Algunos estudios resaltaron la importancia del consumo de bebidas azucaradas ("sugar sweetened beverages, or SSB en inglés) como causa de estos problemas. Según esas estimaciones los SSB aportaban alrededor del $69 \%$ de los azúcares añadidos, el $45 \%$ del consumo total de azúcar y el 10\% de la ingesta total de energía a la dieta mexicana, más del triple del nivel recomendado por la American Heart Association (Alvarez-Sánchez et al., 2018; Colchero, M. A. et al.,2017).

\footnotetext{
${ }^{5}$ https://mof.gov.jm/mof-media/media-centre/press/1570-revised-revenue-measures-sct-on-alcoholic-beverages-and-onenergy-drinks.html

${ }^{6}$ https://www.infobae.com/economia/2017/11/01/una-suba-de-impuestos-a-vinos-cervezas-y-gaseosoas-podria-trasladarse-a-precios/

${ }^{7}$ https://brazilian.report/business/2018/08/27/coca-cola-brazil-tax/; https://www.gazetadopovo.com.br/wiseup-news/will-coca-cola-leave-brazilhow-far-did-soda-aid-go

${ }^{8}$ Impuestos a las bebidas azucaradas como estrategia de salud pública: la experiencia de México (PAHO, 2015)

https://iris.PAHO.org/bitstream/handle/10665.2/18391/9789275118719 eng.pdf?sequence=1\&isAllowed=y
} 
Adicionalmente, otros estudios marcaron el impacto negativo de otros alimentos ricos en grasas saturadas o azúcares añadidos (Aburto et al., 2016).

Por ello, México ha tomado una serie de medidas para combatir el sobrepeso y la obesidad, incluyendo los impuestos discutidos a continuación.

\section{Legislación: visión general}

En enero de 2011 el Congreso de México aprobó una ley con un impuesto equivalente al 25\% sobre las bebidas energizantes (energy drinks) definidas como bebidas no alcohólicas con más de $20 \mathrm{mg}$ por $100 \mathrm{ml}$ de cafeína y mezcladas con estimulantes (por ejemplo, taurina). El impuesto se aplicaba también a los concentrados, polvos y jarabes utilizados para preparar bebidas energizantes. ${ }^{9}$

En enero de 2014 se aprobó un impuesto ad valorem de 8\% sobre la comida "no esencial" con alto contenido calórico, definido como 275 kcal o más por cada 100 gr (IEPS, Impuesto Especial sobre la Producción y los Servicios).

La lista de esos productos incluye los siguientes:

5. Aperitivos.

6. Productos de confitería.

7. Chocolate y otros productos derivados del cacao.

8. Flanes y pudines.

9. Dulces derivados de frutas y verduras.

10. Mantequilla de maní y avellanas.

11. Dulce de leche.

12. Alimentos procesados a base de cereales.

13. Helados, conos de nieve y paletas como papas fritas, productos de confitería, productos a base de chocolate y cacao, "puddings", y otros.

Se estima que estos alimentos contribuyen en promedio $14.4 \%$ a la ingesta total de energía de la población (Batis et al., 2017)

En enero de 2014 también se aplicó un impuesto de MXN\$ 1 por litro de bebida azucarada. Éstas se definen como todas las bebidas con azúcar agregada (refrescos, jugos y sodas), excluyendo las leches o yogures.

La hipótesis utilizada en México para calcular el impuesto sobre bebidas azucaradas fue que la demanda de refrescos en México tendría una elasticidad precio tal que un aumento de los impuestos sobre estos productos desalentaría su consumo, pero fortalecería la capacidad de recaudación de ingresos del país (es decir ni tan inelástica que todo el impacto fuera mayor recaudación, ni tan elástica que el resultado fuera solamente la caída del consumo). Las estimaciones sugerían que un impuesto del $20 \%$, equivalente a MXN 1.7 (US \$ 0.12) por litro de bebida, ayudaría a disminuir el consumo de 163.3

\footnotetext{
${ }^{9}$ https://policydatabase.wcrf.org/level one?page=nourishing-level-one\#step2=2\#step3=315
} 
L a 120.9 L per cápita por año (una reducción del 26\%), con un impacto mayor aún en el quintil más pobre de la población. Se esperaba que esa reducción en el consumo bajaría en un $5 \%$ la prevalencia de sobrepeso y obesidad en adultos dentro de los 10 años y disminuiría la prevalencia de diabetes en casi un $12 \%$, lo que representaba una reducción del 17\% aproximadamente del gasto público destinado a este tipo de enfermedades. Además, se estimaba que se recaudarían cerca de MXN 22,861 millones (unos US\$1,690 millones), lo que, se argumentó, permitiría al gobierno instalar bebederos de agua potable en escuelas y espacios públicos, así como implementar otros programas contra la obesidad y el sobrepeso (PAHO, 2015).

El 31 de octubre de 2013, el Senado concluyó su análisis y, con algunas modificaciones, aprobó la propuesta del Poder Ejecutivo, que finalmente propuso un impuesto equivalente a un aumento de aproximadamente un $10 \%$ en el precio de las bebidas azucaradas y los refrescos, a diferencia de la propuesta parlamentaria inicial, apoyada por el grupo intersectorial, que consideraba un impuesto equivalente al $20 \%$ del precio (lo que fue rechazado en abril de 2013) (PAHO, 2015). Específicamente, el gobierno mexicano implementó un impuesto especial de 1 peso mexicano por litro a todas las bebidas no alcohólicas con azúcar agregado a partir de 1 de enero de 2014. La regulación permite que el impuesto se ajuste cuando la tasa de inflación acumulada en México alcance el 10\%.

Esta iniciativa fue resistida por la industria, que presentó argumentos respecto de la incertidumbre de los resultados favorables estimados, y enfatizó el impacto económico negativo en el empleo y las inversiones. Aunque esta oposición no frenó al impuesto, hizo que la tasa bajara respecto de la propuesta original (PAHO, 2015).

Otro desafío que enfrentó el gobierno fue cómo asignar legalmente los recursos recaudados a través del impuesto a programas específicos como la instalación de fuentes de agua potable en las escuelas y espacios públicos o la prevención del sobrepeso y la obesidad, ya que la política fiscal mexicana generalmente no prevé la asignación específica de los recursos recolectados (PAHO, 2015). ${ }^{10}$

\section{Evaluaciones del impuesto sobre las bebidas azucaradas}

Se han realizado varias evaluaciones del impacto del impuesto a las bebidas azucaradas (AlvarezSánchez et al., 2018; Colchero, et al. 2017).

Los resultados de las evaluaciones sugieren lo siguiente.

- Primero, cerca de 2/3 de la población adulta analizada (en 2014 y 2015), estuvo al tanto del impuesto.

- Segundo, los precios al consumidor de las bebidas con impuestos subieron en la misma proporción del impuesto (es decir, hubo un traslado directo a los precios).

- Tercero, hubo una disminución en el consumo de las bebidas azucaradas (un promedio de cerca del $8 \%$ en 2014 y 2015).

- Cuarto, la caída en el consumo fue mayor en los quintiles de menores ingresos. Debido a eso, se ha argumentado que es un impuesto regresivo. Por otra parte, otros analistas han indicado que, al disminuir más los costos de salud de las enfermedades no transmisibles (directos e indirectos) de

\footnotetext{
${ }^{10}$ Debe notarse que, en general, la teoría fiscal desalienta el uso de asignaciones específicas de impuestos debido a las rigideces que esa práctica genera en el manejo de las cuentas públicas.
} 
los sectores más pobres, este efecto hace que el impuesto no sea regresivo considerando la totalidad de los efectos.

- Quinto, hubo un desplazamiento del consumo hacia otros productos no gravados (bebidas endulzadas con edulcorantes artificiales, agua mineral con gas, agua embotellada, jugos sin azúcares añadidos y leche sin azúcares añadidos); esto sucedió especialmente en los sectores de ingresos medios.

- Sexto, hubo incrementos de la recaudación fiscal en línea con las estimaciones originales, pero, como se dijo, debido a que la legislación mexicana no permite la asignación de impuestos a usos específicos, esos recursos no pudieron utilizarse para algunos de los objetivos de nutrición que se discutieron durante su aprobación parlamentaria (aunque se pudo utilizar parte de la recaudación adicional para proporcionar agua potable a las escuelas públicas, particularmente en las zonas de bajos ingresos, como resultado en parte de una campaña de la sociedad civil para usar los ingresos del impuesto en programas de nutrición).

- Séptimo, las evaluaciones también sugieren que es importante acompañar el impuesto con campañas de educación, ya que al menos con el nivel de tasa impositiva aplicada (aproximadamente un $10 \%)$, y dada la preferencia cultural por esas bebidas, puede ser que el puro efecto precio no sea muy fuerte si no se lo refuerza con otras medidas.

- Octavo, el acceso a agua potable no parece haber tenido efecto adicional sobre el consumo de las bebidas azucaradas.

- Noveno, hay cierta estacionalidad en el consumo, que también hay que considerar al hacer las evaluaciones.

Un punto a notar es que no hay estimaciones del impacto de estos impuestos sobre el empleo y la producción en las cadenas de valor involucradas (ver Piñeiro et al., 2019) para una evaluación ex ante de esas variables en el caso de Guatemala).

\section{Evaluaciones del impuesto a la comida no esencial con alto contenido calórico}

Hay también varias evaluaciones sobre el impuesto a la comida no esencial con alto contenido calórico (comida "chatarra") en México (Taillie, et al., 2017; Hernandez et al. 2018).

Algunos resultados de las evaluaciones son los siguientes. Primero, el traslado del impuesto del $8 \%$ a los precios de los productos fue dispar: por ejemplo, en palomitas de maíz, pasteles, chocolates y dulces, papas fritas y otros bocadillos y barras de cereales, el precio aumentó en línea con la tasa impositiva o más; en otros productos (cacahuetes, cereales para el desayuno, galletas), los precios subieron menos del 8\%; y en un tercer grupo (barras de chocolate o cacao en polvo, bollos dulces), los precios permanecieron sin cambios o se redujeron. Por tanto, el impacto en el consumo también ha sido variado.

Segundo, considerando todos los productos gravados en su conjunto, el trabajo de Hernández et al, 2018 (que utilizó las Encuestas Nacionales de Ingresos y Gastos de los Hogares (ENIGH) de 2008, 2010, 2012, 2014 y 2016), encontró una reducción en las compras de alimentos gravados de $-5.4 \mathrm{~g} /$ semana per cápita, equivalente a una reducción relativa de $-5.3 \%$ en las encuestas de 2014 y 2016 en comparación con las de 2008, 2010 y 2012. Las mayores reducciones relativas se registraron en áreas 
urbanas $(-6.9 \%)$, entre hogares con niños $(-7.0 \%)$, hogares donde el jefe tenía un nivel educativo intermedio $(-9.9 \%)$ y la región sur $(-14.8 \%)$. No encontraron una reducción significativa en las zonas rurales.

Los autores indican que esos resultados son similares a las encontradas en dos estudios anteriores, que estiman una reducción del 5,1\% el primer año del impuesto en comparación con lo que se habría esperado en función de las tendencias antes de impuestos (Batis et al., 2016), y una reducción de $-6.0 \%$ de dos años después de impuestos (Taillie et al., 2017). ${ }^{11}$ Los autores concluyen que si bien existe una gran heterogeneidad, el instrumento fiscal ha sido eficaz para reducir las compras de alimentos gravados y ha generado ingresos fiscales que podrían utilizarse para financiar políticas para la prevención y el tratamiento de la obesidad.

Tercero, el impuesto ha tenido un mayor impacto en hogares que tenían un consumo no saludable, es decir con mayor ingesta de los productos gravados.

Cuarto, como en el caso de las bebidas azucaradas, hay un mayor descenso en el consumo de los hogares de más bajos ingresos. En el estudio de Taillie et al, 2017, se trata también el argumento que, dado que las personas de bajos ingresos tienden a consumir más comida "chatarra," esto sugeriría que un impuesto a esa comida podría ser regresivo; pero al mismo tiempo, como ya se mencionó, los autores argumentan que como los grupos de bajos ingresos, debido a ese consumo también corren mayor riesgo de contraer enfermedades relacionadas con la dieta, el impuesto sería progresivo en relación con la salud de las personas.

\section{El caso de Chile}

Chile es otro país que ha avanzado en una serie de medidas relacionadas para mejorar las dietas de la población, considerando que es un país con una alta prevalencia de obesidad en la niñez, adolescencia y edad adulta, así como una importante carga de diabetes. También se ha señalado que la prevalencia de la obesidad y las enfermedades crónicas relacionadas es mayor entre las personas con un nivel socioeconómico más bajo, medida por el nivel educativo (Caro et al. 2020; y Essman et al., 2018).

Por ello el país ha implementado un conjunto de regulaciones que abarcan, entre otros, el etiquetado frontal de los alimentos (con octógonos negros si se superan ciertos niveles en componentes considerados nocivos), restricciones en la comercialización de ciertos alimentos para niños, e impuestos a las bebidas en función del contenido de azúcar. Acá se analiza brevemente esta última intervención.

Desde el 1 de enero de 2015, Chile ha incrementado al 18\% (desde el anterior valor de 13\%) la tasa del impuesto ad valorem a las bebidas azucaradas que contienen más de 6,25 g de azúcar por $100 \mathrm{ml}$. Las bebidas azucaradas incluyen todas las bebidas no alcohólicas con edulcorantes añadidos, inclusive bebidas energéticas y aguas. Al mismo tiempo, las bebidas azucaradas con menos de 6,25 $\mathrm{g}$ de azúcar por $100 \mathrm{ml}$ recibieron una reducción del impuesto del 13\% al 10\%. Las bebidas como la leche natural y aromatizada, los jugos $100 \%$ de fruta y el agua sin sabor permanecieron libres de impuestos.

\footnotetext{
${ }^{11}$ Hernández et al, (2018) mencionan que esos otros estudios, comparados con el de ellos, tienen menor cobertura poblacional (no proporcio naron estimaciones para comunidades con menos de 50,000 habitantes, que representan el $37 \%$ de la población mexicana) y de productos (no incluyeron pan dulce de panaderías, dulces y chocolates, lo que representa aproximadamente el $20 \%$ de la cantidad semanal ( $\mathrm{g} / \mathrm{semana}$ ) de compras de alimentos gravadas).
} 
Diferentes análisis han marcado la peculiaridad del sistema, al tener una estructura dual para las bebidas con alto y con bajo contenido de azúcar (lo que incluye las bebidas con edulcorantes artificiales). Ese esquema hace que suba el impuesto en $5 \%$ a los productos que están por encima del umbral, pero que se los baje $3 \%$ a los que están por debajo. Esto es diferente del caso de México, que aplica una tasa única a todas las bebidas no lácteas y no alcohólicas que contienen azúcar agregada, pero no grava a las bebidas sin azúcar agregada que contienen solamente edulcorantes artificiales. En este sentido se ha notado que la magnitud del incentivo fiscal (en una u otra dirección) también parece modesta comparada con el standard recomendado por la OMS de un 20\% (Caro et al. 2018; Nakamura et al. 2018).

La evaluación de estas medidas también tiene que considerar que interactúa con otras medidas de impacto como el etiquetado frontal, y las restricciones de comercialización y publicidad para niños.

Caro et al. (2018) realizaron una evaluación del impacto de los impuestos usando un contrafactual (es decir no un antes y después sino proyectando lo que hubiera sido sin el aumento del impuesto y comparando con lo que resultó efectivamente). ${ }^{12}$

Algunos de los resultados de la evaluación son los siguientes.

Precios. El incremento de impuestos en las bebidas con alto contenido de azúcar (que llaman H-SSB) no parece haberse reflejado en alzas similares de precios: 2,0\% para los $\mathrm{H}$-SSB carbonatados y 3,9\% para los H-SSB no carbonatados en relación con los respectivos contrafactuales, en comparación con el aumento de impuestos del $5 \%$ sobre estas bebidas. Esto es diferente de lo que se observó en México, donde los precios de venta de las bebidas azucaradas carbonatadas aumentaron proporcionalmente al tamaño del impuesto.

Los autores notan que la rebaja de impuestos a los productos de bajo contenido (que llaman L-SSB) tuvo resultados variados, pero aparentemente hubo un incremento de los precios de los productos no gravados (estiman que la leche y los jugos $100 \%$ de frutas y verduras aumentaron $1.8 \%$ en el período posterior a impuestos en relación con el contrafactual, y aún más, un 3,2\% en los sectores de bajos ingresos). Esto marca la importancia de analizar los efectos cruzados en toda una serie de consumos, y no solamente el producto gravado.

Cantidades. Los autores encontraron una reducción en las compras de H-SSB del 3,4\% en volumen en relación con el contrafactual, combinación de una disminución del 8.2\% en el volumen de las H-SSB no carbonatadas y una disminución del $2.6 \%$ en el volumen de las $\mathrm{H}$-SSB carbonatadas. Sin embargo, esto implica una reducción pequeña en volumen (108 ml por persona por mes, equivalente a aproximadamente un tercio de una lata de bebida).

Por otra parte, las compras de L-SSB aumentaron considerablemente: 10,7\% en relación con el contrafactual, lo que se traduce en aumentos absolutos de $281 \mathrm{ml}$ por persona por mes (aproximadamente tres quintas partes de una lata de refresco).

Finalmente, debido al aumento de los precios de los productos no gravados, las compras de esos productos cayeron en el período después de impuestos un $3,1 \%$ en volumen.

\footnotetext{
${ }^{12}$ Los autores usaron datos longitudinales recolectados entre el 1 de enero de 2013 y el 31 de diciembre de 2015, de 2,000 hogares. Definieron el período antes de impuestos como el 1 de enero de 2013 al 30 de septiembre de 2014 y el período después de impuestos del 1 de octubre de 2014 al 31 de diciembre de 2015. Compararon los cambios en precios y compras después de impuestos con un contrafactual que proyectaba lo que se habría esperado con base en las tendencias antes de impuestos y que hubieran continuado si no hubieran sido aplicados.
} 
Calorías. Los autores estiman que dado que las cantidades de H-SSB no cayeron mucho, tampoco lo hizo el consumo de calorías relacionados con esos productos: una reducción de 34 calorías por persona por mes para las H-SSB carbonatadas y 21 calorías por persona por mes para las H-SSB no carbonatadas en comparación con sus respectivos contrafactuales. Por otro lado, aunque el volumen de L-SSB subió, al ser de menor cantidad calórica, el impacto en la ingesta de calorías (que los autores indican que no pudieron estimar) puede haber sido menor (aunque sugieren que se monitoree la ingesta de L-SBB, dada la falta de evidencia con respecto a los efectos de más largo plazo sobre la salud debido al consumo de edulcorantes artificiales).

También encontraron que las calorías asociadas al consumo de productos no gravados cayeron un $5,3 \%$, lo que los lleva a concluir que "de manera interesante, la mayor reducción de calorías compradas después del cambio de impuestos provino de productos libres de impuestos en lugar de H-SSB gravados" (page 11). Ese resultado, que puede ser considerado positivo desde el punto de vista de la reducción de calorías, loa autores consideran que debe ser matizado por el hecho que los mismos también tienen nutrientes beneficiosos, como calcio en la leche o vitamina C en jugo 100\% natural.

Concluyen que sus resultados son consistentes con evidencia previa que indica que es poco probable que las pequeñas tasas impositivas sobre las bebidas azucaradas promuevan los cambios en las compras de bebidas azucaradas necesarias para reducir la obesidad y las enfermedades no transmisibles.

El estudio de Nakamura et al. (2018) utilizó un enfoque econométrico de antes y después, para evaluar los cambios a corto plazo (12 meses después de la implementación) en las compras después del impuesto a las bebidas azucaradas, controlando por las condiciones económicas regionales, la temperatura regional y las fluctuaciones estacionales, así como la incorporación de efectos fijos para las características invariantes en el tiempo.

Este trabajo encontró una reducción significativa en el volumen de gaseosas cargadas con altos impuestos $(21,7 \%)$, lo que también se reflejó en una disminución en la cantidad de azúcar agregada comprada de gaseosas $(15,1 \%)$. Pero no encontraron aumentos significativos en el volumen de los productos cargados con impuestos bajos. Esta asimetría la atribuyen a la teoría de Kahneman y Tversky (1979) que sugiere que los consumidores responden con más fuerza a un aumento de precio que a una disminución de precio.

Una de las conclusiones de los autores es que, si bien encontraron que la cantidad de azúcar agregada de los refrescos comprados disminuyó en general, no está claro que el diseño de impuestos analizado sea el más adecuado para maximizar la salud y el bienestar social de la población.

Otro trabajo focalizado en el consumo de bebidas azucaradas de preescolares y adolescentes en Chile (Essman et al., 2018) ha remarcado la importancia del etiquetado frontal con etiquetas nutricionales simples y fáciles de evaluar. Por ello, separar la influencia de diferentes intervenciones, como impuesto y etiquetado, puede no ser simple. 


\section{Impuestos a las Bebidas Alcohólicas}

Un caso especial es el de impuestos a las bebidas alcohólicas. El Gráfico 3 muestra la contribución al consumo de calorías diarias per cápita en los países considerados y en comparación con el promedio mundial.

\section{Gráfico 3: Bebidas Alcohólicas (kcal/cápita/dia)}

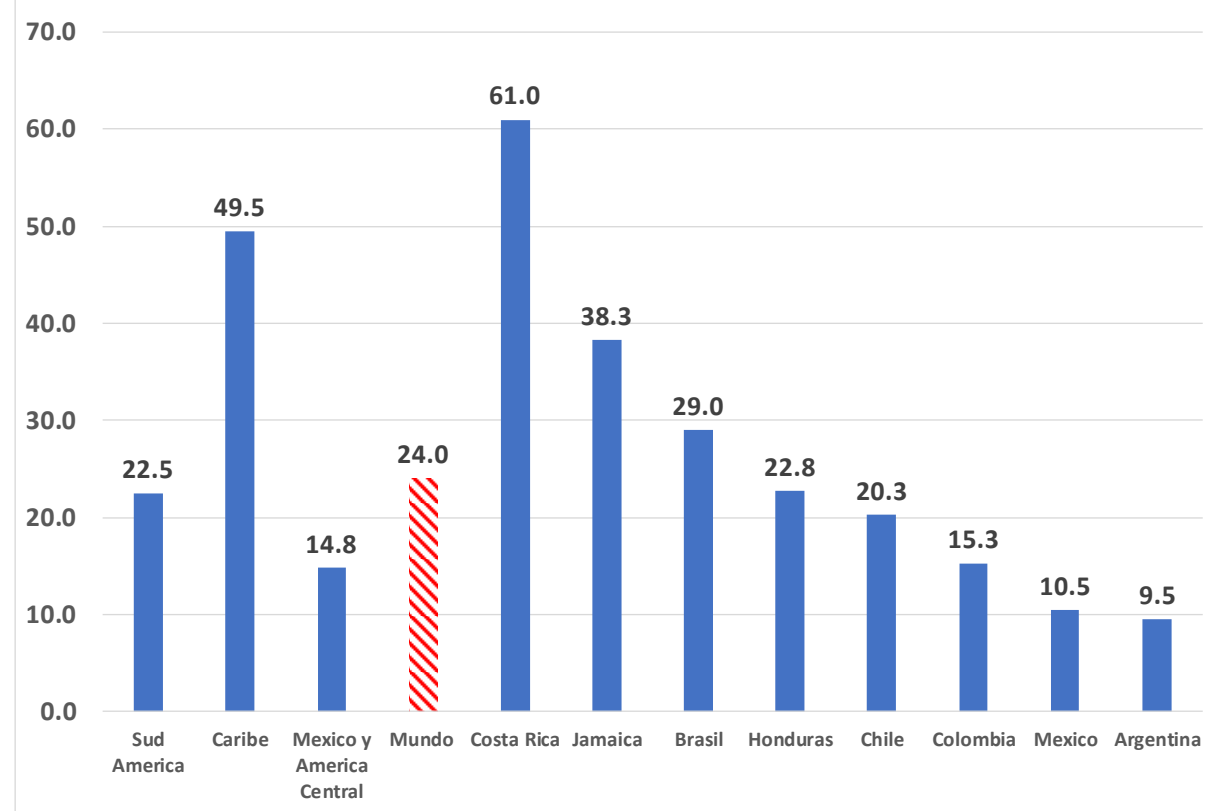

Fuente: autores con datos de Faostat

En América Latina hay una gran disparidad en el nivel de calorías consumidas como bebidas alcohólicas, con altos valores en el Caribe, mientras que, en promedio, Sud América y México y Centro América, están por debajo del mundo. Entre los países considerados, Costa Rica, Jamaica y Brasil están por encima del promedio mundial, Honduras y Chile se ubican alrededor del promedio mundial y de la región, mientras que Colombia, México y Argentina, tienen valores de consumo calórico más bajos que el mundo y la región.

Todos los países considerados tienen impuestos a las bebidas alcohólicas, aunque varían en la cobertura y tasas aplicadas (ver Cuadro 3). Aunque en muchos casos tuvieron su inicio en consideraciones de salud pública, probablemente en la actualidad para muchos países sean simplemente un mecanismo recaudatorio. 


\section{Cuadro 3: Impuestos a las Bebidas Alcohólicas}

En Argentina los vinos, sidras y espumosos pagan el 0\%, las cervezas el 8\%, whisky y coñac $20 \%$. La propuesta en 2017 era que todas las bebidas alcohólicas tuvieran una alícuota impositiva del 17\% y las bebidas como whisky y otras blancas una alícuota entre $20 \%$ y $29 \% .^{13}$

En Colombia, la industria licorera recibió un aumento impositivo tanto en IVA como impuesto al consume. En 2016 se pagaba COL $\$ 220$ por grado de alcoholimetro, impuesto ad valorem de $25 \%$ por sobre el precio de venta sin impuestos e IVA de 5\%. En 2019, el IVA paso a 26\%, el impuesto al consumo paso a $49 \%$ y en 2020 se aplicó COL\$ 245 por grado de alcohol. ${ }^{14}$

En Honduras la importación o venta de cervezas, aguardiente, licor compuesto y otras bebidas alcohólicas tiene un impuesto a la venta del 18\%. (https://www.sar.gob.hn/isv/)

En México, las bebidas alcohólicas pagan dos impuestos: IEPS (Impuesto Especial sobre Productos y Servicios) de 53\% e IVA de $16 \%$. En enero de 2020, el gobierno de la Ciudad de México aplicó un impuesto adicional con una alícuota de $4.5 \%$ a bebidas alcohólicas con grado de alcohol que va de 3 a 55 grados, con excepción de cervezas y aguamiel y sus derivados. ${ }^{15}$

En Brasil el principal impuesto es el Impuesto a los Productos Industrializados (IPI) Cervezas tienen un alícuota de 6\% de IPI, vinos $10 \%$ y entre $20 \%$ y $30 \%$ en bebidas destiladas. Adicionalmente los vinos y espumantes tienen impuestos a la importación de $27 \%$ y $20 \%$ respectivamente. ${ }^{16}$

En Costa Rica el impuesto específico al consumo de bebidas alcohólicas varia dependiendo de su contenido alcohólico (tarifas vigentes hasta 31 de julio de 2020):

- Hasta $15 \%$ de alcohol se cobra colones 3.41 por mililitro.

- Mas de $15 \%$ y Hasta $30 \%$, el impuesto es colones 4.10 por mililitro de alcohol.

- Mas de $30 \% 4.78$.

La Administración Tributaria ajusta de oficio trimestralmente el monto del impuesto de acuerdo con la evolución del IPC, en ningún caso el ajuste trimestral podrá superar el $3 \% .{ }^{17}$

En Jamaica se aplica un impuesto específico al consumo de alcohol basado en el contenido alcohólico de la bebida: J\$ 1,230 por litro de alcohol puro (este valor se aplica desde marzo de 2017). También se aplica un impuesto aduanero a la importación de bebidas blancas como gin, vodka, whisky y run, la tasa es del $35 \% .^{18}$

Chile también aplica impuestos a las bebidas alcohólicas de la siguiente manera: Tasa 31,5\%: para licores, piscos, whisky, aguardientes y destilados, y vinos licorosos o aromatizados similares al vermouth. Tasa 20,5\%: para vinos destinados al consumo, ya sean gasificados, espumosos o champaña, generosos o asoleados, chichas y sidras destinadas al consumo (cualquier que sea su envase, cerveza y otras bebidas alcohólicas). ${ }^{19}$

Fuente: elaboración de los autores

\footnotetext{
${ }^{13}$ https://www.infobae.com/economia/2017/11/01/una-suba-de-impuestos-a-vinos-cervezas-y-gaseosoas-podria-trasladarse-a-precios/

${ }^{14}$ https://www.larepublica.co/empresas/estas-son-las-nuevas-condiciones-que-enfrentara-el-sector-licorero-para-2019-2812218

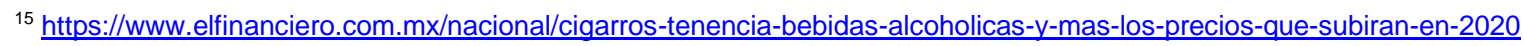

${ }^{16}$ http://usdabrazil.org.br/en/reports/changes-to-brazils-excise-tax-on-industrialized-products-ipi.pdf

${ }^{17}$ https://www.hacienda.go.cr/contenido/14430-tarifas-impuesto-especifico-de-consumo-sobre-bebidas-alcoholicas; http://www.pgrweb.go.cr/scij/Busqueda/Normativa/Normas/nrm_texto_completo.aspx?param1 $=$ NRTC\&nValor1 $=1 \&$ nValor2 $=52256 \&$ nValor3 $=56670 \&$ strTipM $=\overline{\mathrm{T} C}$

${ }^{18} \mathrm{https}: / /$ mof.gov.jm/downloads/speeches/presentations/who-monitoring-evaluating-ja-alcohol-tax-policy-2018.pdf

${ }_{19} \mathrm{https://www.rankia.cl/blog/sii/3350134-impuesto-bebidas-alcoholicas-analcoholicas-definicion-ejemplos-tasas}$
}

http://www.sii.cl/preguntas frecuentes/iva/001 030 1250.htm

http://www.sii.cl/ayudas/aprenda sobre/3072-3-3079.html 


\section{E. SUBSIDIOS Y EXENCIONES IMPOSITIVAS AL CONSUMO DE ALIMENTOS SALUDABLES}

También en este caso se comentan solamente algunas políticas fiscales internas (a diferencia de las políticas de comercio internacional, que se discuten más adelante) que bajan directamente el precio que paga el consumidor por los alimentos. ${ }^{20}$

\section{Exenciones impositivas}

Una medida bastante común es la exención del impuesto a las ventas o del impuesto al valor agregado en el caso de los alimentos. Por lo general, son exenciones a los alimentos, pero sin distinguir su calidad nutricional.

Por ejemplo, Honduras, decidió en junio de 2015 una exención impositiva del 15\% sobre el impuesto a las ventas en alimentos básicos, agua purificada, medicamentos y productos farmacéuticos, agroquímicos, materiales educativos, maquinaria y equipos para la generación de energía eléctrica, maquinaria y herramientas agrícolas, artesanías, bienes de capital como camiones, tractores, grúas, computadoras y equipos utilizados para la industria maquiladora (ITA, 2019). Costa Rica tiene exenciones impositivas sobre el impuesto a las ventas sobre productos alimenticios básicos (arroz, frijoles, papas, etc) (OECD, 2017a). En Jamaica los alimentos básicos están exentos del pago del impuesto al consumo general (la tasa que se aplica al resto de los bienes es del 16.5\%). En Brasil el Impuesto al Valor Agregado sobre la circulación de bienes y servicios (ICMS) se reduce del 17\% al 7\% para los productos básicos (Ter-Minassian, 2012). También en Brasil, se presentó al congreso en 2015 una propuesta de reducción de impuestos sobre la comida saludable que no fue aprobada por el Congreso (Santarelli, Marques Vieira, and Constantine, 2018). Separadamente, el gobierno de Brasil ha firmado, en 2018, un acuerdo voluntario con algunas empresas del sector alimenticio de reducción de azúcar para el año 2022 (Presidency of the Republic of Brazil, 2018).

Por su parte, Argentina eliminó en diciembre de 2019 el cobro del IVA sobre algunos alimentos básicos como medida temporal (aceite de girasol y de maíz, arroz, azúcar, fruta en lata, vegetales en lata, frijoles secos, harina de maíz, harina de trigo, huevos, leche entera y desnatada, pan, pan rallado, mantequilla, pasta seca, yerba mate, té y yogurt entero y desnatado) (Presidencia Argentina, 2019). Colombia aplica un IVA del $0 \%$ sobre alimentos básicos, incluyendo la venta de animales vivos utilizados para consumo humano, vegetales, semillas, frutas y otros productos agrícolas, frescos o congelados, la venta de carne de res, cerdo, oveja y cabra; ciertas aves de corral, camarones, huevos, leche, pescado, frescos, refrigerados, por los productores de dichos productos, y un IVA del $5 \%$ (en lugar de 19\%) a productos agrícolas (Societe Generale, 2020).

\footnotetext{
${ }^{20}$ En principio cualquier política que baja el precio al consumidor y expande el consumo, va a tener algún impacto en el precio del productor (ver Gráfico 2).
} 


\section{Otras modalidades de ventas a precios subsidiados y/o distribución gratuita de alimentos}

Algunos países de la región tienen mecanismos estatales de venta al público con precios subsidiados. Un paso adicional a la venta con precios subsidiados es simplemente la distribución gratuita de alimentos, que a su vez puede tomar diferentes formas. Los programas alimentarios en varios países tienen ejemplos de programas con precios subsidiados y distribución gratuita de alimentos. Pero usualmente, los productos elegidos se basan más en criterios relacionados con los niveles de energía (calorías) y no en las características nutricionales más amplias.

En el caso de precios subsidiados, México ha operado desde 1972 una cadena pública de más de 27,000 tiendas en todo el país (DICONSA), que proporcionan alimentos básicos y otros bienes esenciales a precios subsidiados a la población rural y urbana marginal, llegando a más de 47 millones de personas. Las tiendas son abastecidas por una red de almacenes centrales y regionales y varios miles de camiones de reparto para llegar incluso a las áreas más remotas. Este programa se complementa, a partir de 1995, con otro denominado LICONSA que provee leche fortificada subsidiada a más de 8 millones de beneficiarios vulnerables en todo el país (FAO, 2016).

Brasil tiene un programa que abarca comedores populares, cocinas comunitarias y bancos de alimentos, como parte una red de protección alimentaria para apoyar a los sectores más vulnerables (Brasil Sem Miséria) y es ejecutado por el Ministerio de Desarrollo Social y Lucha contra el Hambre (ECLAC, 2017a).

La modalidad de "Restaurantes Populares" entrega alimentos a precio de costo a los sectores sociales de más bajos ingresos (trabajadores formales e informales de bajos ingresos, desempleados, estudiantes, personas en situación de calle), y que deban alimentarse fuera de casa. Los restaurantes populares son establecimientos que comercializan raciones rápidas, pero que sean nutricionalmente balanceadas y de calidad asegurada. El programa se está implementando preferentemente en municipios de tamaño grande y mediano, y a través de su acción, se busca crear una red de protección alimentaria en zonas donde exista un alto número de personas que no comen en sus hogares.

El componente de "Bancos de Alimentos" tiene como objetivo incentivar y apoyar la creación de bancos públicos de alimentos, mediante la capacitación y la transferencia de tecnología, y reducir el desperdicio de alimentos en el combate al hambre. El componente se focaliza en el sector de la población brasileña en situación de vulnerabilidad alimentaria, que vive en municipios de tamaño grande y mediano. Los Bancos de Alimentos operan a través de la recepción de donaciones de productos que, por distintas razones, no son apropiados para la comercialización, pero que mantienen inalteradas sus propiedades nutricionales. Estos productos son entregados para su distribución a organizaciones no gubernamentales sin fines de lucro.

La modalidad de "Cozhinas Comunitárias" incluye equipamientos públicos de alimentación y nutrición destinados a la preparación de comidas saludables y variadas, las cuales son distribuidas gratuitamente $o$ a precios accesibles a la población en situación de vulnerabilidad social, garantizando a ese sector el derecho humano a una alimentación saludable. Cada una de ellas se encuentra comprometida con la producción mínima de 100 comidas por día, durante por lo menos 5 días a la semana, respetando siempre las características culturales y hábitos alimenticios de la región. Actualmente existen 407 unidades que funcionan en 22 estados del país, entregando cerca de 87 mil comidas diarias. 


\section{Programas escolares y materno-infantiles}

Los programas más comunes de distribución gratuita de alimentos son los comedores escolares, que funcionan en todos los países de la región (ver también el documento de Birmayr-Jenzano 2020, que complementa este trabajo). Otro programa generalizado es el de alimentación materno-infantil.

Por ejemplo, Costa Rica tiene ambas modalidades (como la mayoría de los países de la región). El programa de alimentación escolar clasifica las escuelas en distintos niveles de prioridad de acuerdo con un mapa de pobreza. Las escuelas de prioridad 1 son las de los estratos más pobres y las escuelas con un solo maestro y menos de 100 estudiantes. Las escuelas de prioridad 2 incluyen aquéllas en los estratos de pobreza intermedia, así como las de estratos de ingresos más altos, con una cantidad de entre 100 y 500 alumnos. Las escuelas de prioridad 3 incluyen todas las escuelas en los estratos más acomodados y con más de 500 estudiantes. Dados los tres niveles de beneficios, y la cantidad de subsidio por almuerzo por niño, se asignan los recursos a cada escuela en función de su tamaño y la calificación de pobreza del área a la que sirve, de acuerdo con el mapa de pobreza del Ministerio de Planificación. Es un ejemplo de focalización geográfica y no individual.

Un tema relacionado es que, en 2012, mediante un decreto del poder ejecutivo, se prohibió la venta de comida "chatarra" y bebidas azucaradas que superan los $6 \mathrm{gr} / 100 \mathrm{ml}$ (SSB) de los centros escolares públicos. Sin embargo, las escuelas privadas no están obligadas a cumplir con esta regulación (Bergallo et al. 2018).

Por su parte, los centros de nutrición CEN-CENA en Costa Rica proporcionan: a) guardería con alimentación, educación nutricional, monitoreo del crecimiento y educación de la primera infancia; b) un programa de leche para llevar a casa; y c) una canasta familiar para llevar a casa. La focalización se basa en la ubicación geográfica, las referencias de expertos, la situación laboral de las madres y los puntajes de riesgo psicosocial computados mediante el uso de un formulario simple. Los niños tienen acceso de acuerdo con las siguientes prioridades: a) aquellos que están desnutridos, maltratados o abandonados, los referidos por una institución o aquellos con puntajes de riesgo de al menos 40; b) niños cuyas madres trabajan fuera del hogar y que tienen puntajes de riesgo de 50 o más; c) niños cuyas madres no trabajan fuera del hogar y tienen puntajes de riesgo de 60 o más. Las guarderías también requieren que los niños vivan en un radio de $1 \mathrm{~km}$. Los niños desnutridos se identifican a través de los centros de salud locales (FAO, 2001).

En Jamaica, el Programa de Alimentación Escolar selecciona las escuelas en base a la estimación del Ministerio de Educación sobre qué escuelas están ubicadas en áreas pobres. Se trata de una entrega diaria de productos alimenticios desde locales centrales, lo que lleva a que las escuelas con acceso a buenos caminos tienden a ser mejor atendidas que las de zonas más remotas. Aproximadamente el $72 \%$ de los beneficios van al 40 por ciento más pobre de la población (FAO, 2001).

Otro caso es México que ha combinado varios programas alimentarios: desayuno escolar; cuidado a niños en riesgo menores de 5 años que no están en la escuela; asistencia alimentaria a personas vulnerables; y ayuda alimentaria a familias en peligro. Estos cuatro programas han sido parte de la Estrategia Integral para la Asistencia Social Alimentaria (EIASA), cuyo objetivo es contribuir a mejorar la calidad de vida de los receptores de asistencia social que tienen una nutrición deficiente o están en riesgo.

También Honduras tiene un esquema con varios componentes que se articulan alrededor de los comedores escolares. Al comienzo del año escolar, los maestros de escuela primaria en los departamentos 
participantes deben identificar a los estudiantes de hogares encabezados por mujeres y con ingresos por debajo de un nivel establecido. Una vez identificados estos niños, se entregan cupones alimentarios a las madres. Se ha estimado que alrededor de 13,000 docentes participan en los siete departamentos donde opera el programa. El programa beneficia a aproximadamente 125,000 estudiantes por año en los grados 1 a 3. También se entregan cupones de alimentos a través de centros de salud en Honduras para el beneficio de niños menores de cinco años y para mujeres embarazadas y lactantes, que son identificadas a través de la vigilancia nutricional (FAO, 2001).

Por su parte el programa de alimentación escolar comprende una ración diaria de 160 gramos de alimento, cuyo costo sin cocinar es de Lps. 2.50/ alumno y consiste en 30 gramos de arroz, 25 gramos de frijol, 60 gramos Harina de Maíz fortificada, 10 gramos de aceite y 1 huevo. La distribución de Alimentación Escolar con Ración Básica se realiza en tres entregas en el año escolar en los centros educativos del sector público; este alimento llega a las bodegas municipales cada 40 días para cubrir el proceso requerido de entrega a las diferentes escuelas con cobertura de nivel nacional (Gobierno de la República de Honduras, 2020).

Aunque se supone que la alimentación escolar debe ser saludable, los criterios al respecto varían, y en general, parecen estar más inclinados a satisfacer el consumo de calorías, sin otros objetivos nutricionales más saludables. Algunas excepciones son México que desde 2007 tiene un enfoque de los programas de alimentación que considera la doble carga del sobrepeso y la desnutrición que afecta al país, y Brasil que ha determinado que el $70 \%$ del presupuesto destinado al almuerzo escolar en las escuelas federales debe destinarse a alimentos no procesados y el $30 \%$ restante debe provenir de la producción agrícola familiar (Presidência da República de Brasil, 2009).

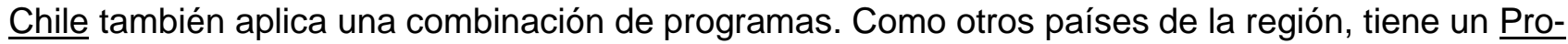
grama de Alimentación Escolar que entrega diariamente servicios de alimentación (desayunos, almuerzos, once, colaciones y cenas según corresponda) a los alumnos y alumnas en condición de vulnerabilidad de Establecimientos Educacionales Municipales y Particulares Subvencionados del país durante el año lectivo adscritos al Programas de Alimentación Escolar, en los niveles de Educación Parvulario (Pre-Kínder y Kínder), Básica, Media y Adultos. A diferencia de otros programas, cubre tanto actividades curriculares como extracurriculares, durante el año lectivo y en vacaciones de invierno y verano.

Se entrega una ración diaria de alimentación por estudiante, complementaria y diferenciada, compuesta por: desayuno, almuerzo y/u "once" (el nombre en Chile de una cena ligera o un snack tardío); además en hogares se entrega desayuno, almuerzo, once y cena. Las raciones cubren alrededor de un tercio de las necesidades nutricionales del día de los escolares de enseñanza básica y media y entre un 45 y un $50 \%$ de los requerimientos de los preescolares y en el caso de los hogares el $100 \%$ del requerimiento diario de los alumnos y alumnas beneficiarias. Se atiende a los alumnos de familias que pertenecen al $60 \%$ más vulnerable o con mayor desventaja socioeconómica según registro social de hogares, que asisten a establecimientos educacionales municipales y particulares subvencionados del país (que estén adscritos al PAE), en los niveles de educación pre-básica, básica, media y adultos (Ministerio de Educación Gobierno de Chile, 2020).

Existe un programa adicional (Tercer Servicio del Programa de Alimentación Escolar) que entrega una colación diaria de refuerzo a niños, niñas y jóvenes estudiantes que participan del Subsistema Chile Seguridades y Oportunidades. Para hacer efectivo este beneficio, los estudiantes deben estar matriculados en establecimientos educacionales municipales y particulares subvencionados, de educación general y especial, adscritos al PAE durante el año lectivo en los niveles de Educación Parvulario (Pre- 
Kínder y Kínder), Básica y Media. El beneficio se deja de entregar cuando el alumno finaliza sus estudios de enseñanza media o se retira del sistema escolar.

Chile también implementa un Programa Nacional de Alimentación Complementaria, para madres gestantes, madres que amamantan, niños y niñas menores de 6 años, prematuros extremos y menores de 25 años con enfermedades metabólicas. Cada grupo recibe alimentos complementarios según sus necesidades específicas (Ministerio de Salud Gobierno de Chile, 2020).

\section{Otras modalidades}

En lugar de reducir el precio de compra del consumidor (y en el límite, entregar los alimentos gratis), otra opción es incrementar los ingresos, mediante apoyos económicos, con un foco en la compra de alimentos. En la región hay una variedad de programas de transferencias de ingresos, con componentes alimentarios, y/o tarjetas o vouchers alimentarios. En el trabajo complementario de Patricia Biermayr (2020) se discuten varios de esos programas como Progresa/Oportunidades/Prospera de México, creado en 1997 (que recientemente ha sido suspendido y está siendo reevaluado) o el programa Bolsa Familia de Brasil, creado en octubre de 2003, y otros similares.

\section{F. COMBINACIÓN DE IMPUESTOS AL CONSUMO DE ALIMENTOS NO SALUDABLES Y SUBSIDIOS AL CONSUMO DE ALIMENTOS SALUDABLES}

No parece haber programas que combinen impuestos al consumo de alimentos no saludables y subsidios al consumo de alimentos saludables como un paquete integrado. Existe un ejercicio interesante de calcular el posible efecto de esa combinación en el caso de Chile (Juan Carlos Caro, Pourya Valizadeh, Alejandrina Correa, Andres Silva, Shu Wen Ng, Enero 15, 2020). Los autores tratan de simular el impacto de un esquema de política alimentaria combinado que aumente la diferencia de precios relativos entre alimentos saludables y no saludables vía impuestos y subsidios, al tiempo que se analiza el cambio de bienestar del consumidor usando la variación de compensación (CV ${ }^{21}$ para cada hogar debido a cambios en los precios.

Los autores utilizan la Encuesta ingresos y Presupuestos de los Hogares (2016-2017) ${ }^{22}$ para analizar el impacto de tres políticas fiscales: un impuesto del $18 \%$ a los dulces y bocadillos salados y un aumento adicional de 5 puntos porcentuales al ya existente impuesto a las bebidas azucaradas (que se discutió anteriormente) (política 1); la aplicación de una tasa cero sobre frutas y verduras en lugar del actual impuesto al valor agregado (IVA) del 19\% (política 2); y una combinación de ambas estrategias (política 3).

\footnotetext{
${ }^{21}$ La CV mide cuánto dinero necesita recibir (o pagar) un hogar para quedar tan bien después de un aumento (disminución) en el precio como lo estaba antes del cambio de precio.

${ }^{22}$ EI EPF se realiza cada cinco años en las principales áreas urbanas, que representan el $74 \%$ de la población urbana. Se recopilan datos sobre cantidades y gastos en todos los artículos (es decir, alimentos y no alimentos) utilizados para construir las ponderaciones del Índice de Precios al Consumidor, así como información socioeconómica y demográfica de los hogares (utilizada para definir líneas de pobreza, entre otras aplicaciones). Se entrevistó a un total de 15,239 hogares entre julio de 2016 y junio de 2017.
} 
Las simulaciones se basan en estimaciones de los autores acerca de la demanda de alimentos, calculando la elasticidad ingreso, precio y precios cruzados de varios grupos de productos. También analizan la posible heterogeneidad de los impactos de las políticas debida a la distribución de los ingresos.

Las estimaciones de los autores sugieren que subir los impuestos a productos no saludables (política 1) llevarían a una disminución general de las compras del 13,4\% (1,39 kilogramos) de dulces y bocadillos y del 3,4\% (0,7 litros) de bebidas. También encuentran algo de sustitución hacia las compras de hortalizas $(0,8 \%$ o 0,23 kilogramos).

La eliminación del IVA sobre frutas y verduras (política 2) conduciría a un aumento general del 14,8\% (1,33 kilogramos) de frutas y 13,07\% (3,73 kilogramos) de verduras, sin afectar significativamente las cantidades compradas de dulces, snacks y bebidas.

Finalmente, la política 3, que combina las dos anteriores, muestra resultados que son casi una combinación lineal de las mismas, traduciéndose a nivel de un hogar promedio en un aumento de las compras de frutas y hortalizas en 5.29 kilogramos por mes (1.33 y 3.96 kilogramos respectivamente), mientras que disminuyen las compras de dulces y bocadillos del hogar promedio en 1.43 kilogramos por mes y se reducen las compras de bebidas azucaradas en 0,9 litros por mes.

La política combinada, al subir unos impuestos y bajar otros, es prácticamente neutral respecto del bienestar de los hogares en promedio (un incremento de $0,08 \%$ de los ingresos mensuales), con los cambios absolutos más grandes en los hogares de mayores ingresos. También encuentran un cierto efecto redistributivo hacia los hogares de menores ingresos: una transferencia desde los hogares de mayores ingresos de 3,32 USD por mes, equivalente a 0,06\% de sus ingresos mensuales hacia los hogares de menores ingresos, unos 0,99 USD por mes o $0,23 \%$ de los ingresos mensuales de este último grupo.

Estas simulaciones sugieren la importancia de visiones integradas en el uso de impuestos y subsidios.

\section{G. SUBSIDIOS Y EXENCIONES IMPOSITIVAS A LA PRODUCCIÓN DE ALIMENTOS}

En las secciones anteriores se revisaron políticas orientadas al consumo (aunque como se mencionó en el marco conceptual, el cambiar precios del consumidor normalmente también afecta la producción).

En esta sección se analizan las políticas orientadas a la producción. Usualmente, los apoyos fiscales a la producción agro-alimentaria se miden con la metodología de la OECD (2020), que comprende un conjunto de indicadores que miden las transferencias económicas a los agricultores y consumidores como resultado de la implementación de políticas y programas agrícolas. Las transferencias pueden tener su origen en el gasto público o en políticas que modifican los precios que reciben los productores y pagan los consumidores. Ejemplos de estas últimas son aranceles o impuestos a las importaciones, cuotas de importación, subsidios o impuestos a las exportaciones, y precios administrados. La aplicación de dicha metodología es un ejercicio muy importante de cuantificación de dichas políticas en lo que hace a productos alimentarios primarios o con relativamente bajo nivel de procesamiento; pero no se consideran productos con mayores niveles de procesamiento. 
Centrándose en el enfoque de la OECD, una forma simplificada de entender esas estimaciones es pensar que las transferencias hacia (o desde) productores tienen dos componentes principales: uno está más relacionado con las políticas de comercio internacional que hacen que el precio interno que reciben los productores y que pagan los consumidores (antes de otras subvenciones o impuestos), difieren del precio equivalente de los mercados mundiales para productos comparables (ajustados por calidad, características, márgenes de comercialización, etc.); el otro componente, tiene que ver con el gasto público destinado a apoyar productos y/o productores, o subsidiar a los consumidores. El primer componente captura los flujos (positivos o negativos) entre productores y consumidores (usualmente vía políticas comerciales); y el segundo, entre productores y contribuyentes (usualmente mediante políticas fiscales).

A su vez, el segundo componente puede separarse entre las transferencias fiscales a productores o productos agropecuarios individuales, por una parte, y gastos orientados a todo el sector, por la otra. Entre las primeras se encuentran, por ejemplo, subsidios a precios de productos, que pueden estar basados en diferentes criterios respecto si es producción actual, pasada o no producción es necesaria, a insumos, a bienes de capital, u otras modalidades. ${ }^{23}$ Las segundas intervenciones son gastos públicos de una naturaleza más general, como riego y drenaje, investigación agrícola, servicios de extensión y servicios de inspección de plantas y animales. ${ }^{24}$ A estos últimos de los considera "bienes públicos," por oposición a la primera categoría de subsidios y transferencias a productos o productores individuales, que a veces se los llama "bienes privados." 25

En esta sección nos centramos en las transferencias presupuestarias a productores o productos agropecuarios individuales (mediante subsidios específicos), pero también pueden ser transferencias negativas, como impuestos. Por otra parte, algunos de los subsidios pueden no ser fiscales, como en el caso de créditos subsidiados, si es que el costo del subsidio no lo paga el presupuesto sino el sistema bancario y los depositantes.

\footnotetext{
${ }^{23}$ La lista de intervenciones que componen lo que se llama "Estimado de Apoyo al Productor" incluye lo siguiente; A. Apoyo basado en la producción de productos básicos (A.1. Apoyo a los precios de mercado (MPS): transferencias de consumidores y contribuyentes a productores agrícolas que surgen de medidas de política que crean una brecha entre los precios del mercado interno y los precios en frontera de producto agrícola, medido al nivel de la puerta de la finca. A.2. Pagos basados en la producción: transferencias de los contribuyentes a los productores agrícolas de las medidas de política basado en la producción actual de un producto agrícola específico.) B. Pagos basados en el uso de insumos: transferencias de los contribuyentes a los productores agrícolas derivadas de medidas de política basado en el uso de insumos en la finca (B.1. Uso de insumos variables; B.2. Formación de capital fijo; B.3. Servicios en la finca)

C. Pagos basados en Area /Animales/Ventas/Ingresos actuales con producción requerida (C.1. Basado en ingresos/ventas corrientes; C.2. Basado en el área actual/número de animales)

D. Pagos basados en Area /Animales/Ventas/Ingresos no corrientes, producción requerida

E. Pagos basados en Area/Animales/Ventas/Ingresos no corrientes, producción no requerida (E.1. Tasas variables; E.2. Tarifas fijas)

F. Pagos basados en criterios distintos de los productos básicos (F.1. Retiro de recursos a largo plazo; F.2. Un producto no básico específico: transferencias para el uso de recursos agrícolas para producir productos y servicios no básicos específicos que no son requeridos por las regulaciones; F.3. Otros criterios no relacionados con los productos básicos)

G. Pagos varios

${ }^{24}$ La lista de intervenciones que componen lo que se llama "Estimado de Apoyo a Servicios Generales" (EASG) es como sigue:

H. Conocimiento Agropecuario y Sistema de Innovación (H1. Generación de Conocimiento Agropecuario; H2. Transferencia de Conocimiento Agropecuario; H2a. Educación; H2b. Servicios de Extensión)

I. Inspección y Control (11. Inocuidad de Productos Agropecuario e Inspección; I2. Inspección y Control de Plagas y Enfermedades; I3. Control de Insumos;

J. Desarrollo y Mantenimiento de Infraestructura (J1. Infraestructura Hidrológica; J2. Almacenamiento, Mercadeo y Otras Infraestructuras Físicas; J3. Infraestructura Institucional; J4. Restructuración de Fincas)

K. Comercialización y Promoción (K1. Esquemas Colectivos para Procesamiento y Mercadeo; K2. Promoción de Productos Agropecuarios)

L. Costo de Almacenamiento Publico

M. Misceláneos

${ }^{25}$ La metodología de la OECD también considera otra categoría que son las transferencias a los procesadores agrícolas y otros consumidores de producción agrícola son capturadas por el indicador de Estimación de Apoyo al Consumidor (CSE en inglés).
} 
Finalmente, hay que notar que se tratan de apoyos a la producción agropecuaria en general, y no necesariamente tienen relación con temas de alimentación saludable.

Un caso de apoyo a la producción de alimentos saludables es el "Programa de Innovación en Alimentos + Saludables" de $\underline{\text { Chile, }}$ que busca fomentar la innovación y el emprendimiento de la industria de producción de alimentos saludables, principalmente generando y sistematizando información adquirida de diversas instituciones, apoyando la investigación, desarrollo e innovación, y analizando las tendencias de mercado, entre otras medidas. Para esto promueve el acceso de los productores a los mercados, crea y fortalece redes de información que contemplan diversas dimensiones, y otorga asistencia técnica. Se busca responder a las asimetrías de información en las cadenas de valor local.

Sin embargo, el objetivo no parece ser la mejora de las dietas saludables internamente, sino impulsar en Chile una industria de alimentos más saludable, que pueda ganar posición en los mercados sobre la base de los aspectos de inocuidad, cumplimiento de los estándares de nutrientes críticos y su funcionalidad, que hoy demandan los principales mercados mundiales. Se busca que los empresarios y emprendedores del sector agroalimentario nacional estén en condiciones de abordar mercados que muestran una demanda cada vez más dinámica por productos saludables, a la vez que se busca facilitar la agregación de valor y la generación de nuevos negocios en la industria de alimentos (ECLAC, 2017b).

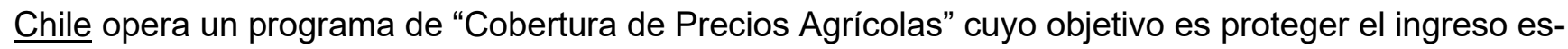
perado de los productores de trigo y maíz, disminuyendo el riesgo frente a fluctuaciones adversas en los precios internacionales de sus productos, a través de un instrumento compuesto de dos coberturas: una Opción Put sobre Contratos de Futuros; una Opción sobre Tipo de Cambio. Es así como a través de la Cobertura de Precios de Productos Agrícolas, el productor de trigo o maíz puede fijar un precio mínimo aproximado de su producto en pesos chilenos, tomando como referencia un mercado internacional (ECLAC, 2017c).

Varios de los programas de subsidios de seguros agropecuarios para resguardar principalmente de desastres naturales y eventos climáticos, cubren productos con diferentes valores nutricionales, como arroz, avena, cebada, maíz, trigo, frutas y producción bovina.

Otros países han implementado una variedad de programas de apoyo a la producción agropecuaria. Pero como se mencionó, los objetivos no necesariamente tienen que ver con las dietas nacionales saludables, sea por el tipo de productos promocionados o porque se orientan a la producción para mercados internacionales.

Por ejemplo, $\underline{\text { Honduras, }}$ tiene una ley de incentivo a la producción de banana. La empresa de exportación paga al productor independiente por cada caja de 40 libras de bananas de áreas rehabilitadas y replantadas US $\$ 0,50$ durante los primeros tres años y US\$ 0,30 durante los próximos tres años. Estos pagos a productores independientes se reconocen como gastos en el cálculo de la renta imponible del exportador (Hernández Ore et al. 2016).

México ha tenido una variedad de programas para apoyar el agro. El más importante ha sido Procampo creado en 1994, y que en 2014 cambió su nombre a Proagro. Los cultivos beneficiados han sido algodón, arroz, cártamo, cebada, frijol, maíz, sorgo, soja y trigo, cuya importancia en relación con dietas saludables es variada. Otra iniciativa, el Programa Incentivo complementario al Ingreso Objetivo, garantiza un ingreso mínimo a los pequeños y medianos productores de granos y oleaginosas, pagándoles la diferencia entre un ingreso predeterminado (llamado "ingreso objetivo") y el precio de mercado 
reconocido por la Agencia de Servicios y Apoyo a la Comercialización Agrícola (ASERCA). Se dirigen en general a los productores y no necesariamente en particular a productos saludables.

Costa Rica tiene un precio mínimo de referencia para el arroz, basado en un análisis de costos de producción nacional realizado por la Corporación Nacional de Arroz (CONARROZ), que es relativamente alto a nivel mundial. Esto favorece la producción, pero a la vez eleva el precio al consumidor, ya que para sostenerlo tiene que usar políticas de comercio internacional que penalizan el consumo, y benefician a un reducido número de grandes terratenientes y molineros de arroz (ver la sección sobre políticas de comercio internacional).

Por otra parte, existen subsidios para la formación de capital fijo, uno de cuyas aplicaciones, administrada por INDER, es para que pequeños productores pobres puedan crear módulos de producción alimentaria de autoconsumo, lo que se espera que mejore la nutrición de esas familias. La política agroambiental del gobierno costarricense incluye pagos directos por servicios ambientales a través de varios fondos, uno de los cuales apunta al Reconocimiento de Beneficios Ambientales para la Producción Orgánica (RBAO); que apoya a productores orgánicos con un pago directo por un período máximo de tres años; existen otros incentivos impositivos y financieros a la producción orgánica, pero el objetivo es ambiental y no tanto nutricional (OECD, 2017a).

Colombia también tiene una variedad de programas de apoyo a la agricultura, con diferentes objetivos. Quizás el más directamente ligado al apoyo de producciones saludables es el programa de 5 años de beneficios fiscales para productores de hortalizas en Cundinamarca (área principal de producción de alimentos, $42 \%$ de la producción nacional de hortalizas), y subsidios de hasta $30 \%$ para ciertos proyectos agrícolas en esa región (Smit, Snijders, and van den Bos, 2014).

Brasil asimismo opera una amplia gama de medidas de apoyo a la producción agropecuaria, varios de ellos dirigidos a pequeños productores, que tienden a ser los principales oferentes de alimentos en el mercado local. El Programa Nacional para Fortalecer la Agricultura Familiar (PRONAF), creado en 2006 para financiar las inversiones agrícolas familiares, se amplió con nuevas líneas de crédito. Por ejemplo, desde 2008, el Programa Mais Alimentos proporcionó líneas de crédito subsidiadas a los agricultores rurales para inversiones en la modernización de infraestructura y maquinaria. Desde 2010, el Programa de Apoyo a Productores Agrícolas de Mediana Escala (PRONAMP) y el Programa de Agricultura de Bajo Carbono financiaron actividades rurales de micro, pequeños y medianos agricultores mediante subsidios de crédito con el objetivo de aumentar los ingresos y la generación de empleo en la agricultura. La principal institución que proporciona crédito rural a tasas subsidiadas o que actúa como garante ha sido el Banco Nacional de Desarrollo (BNDES) (FAO, 2014).

Un aspecto a remarcar ha sido la inclusión de alimentos saludables producidos por pequeños productores familiares en la adquisición de alimentos institucionales (almuerzos escolares, hospitales, instituciones públicas). En 2014, se estimó que alrededor del 23\% de los alimentos del sector público era suministrado por pequeños productores familiares (Santarelli, Marques Vieira, and Constantine, 2018).

Argentina ha tenido en algunos períodos subsidios a los productores de algunos productos como los lácteos en 2007 y 2008 que recibieron un subsidio del 5\% del precio por litro de leche, siempre que acordaran cumplir con los precios máximos establecidos por las autoridades. En 2010, el subsidio aumentó ligeramente. También se pagaron subsidios a los productores de ganado que complementaban la alimentación con granos, con el objetivo de reducir los costos de producción. El mismo tipo de subsidios se aplicó a la carne de cerdo y aves de corral (Lema et al. 2018). 
El Cuadro 4 muestra el cálculo de lo que en la base de datos de Agrimonitor se llaman transferencias de los contribuyentes a productores, para algunos productos específicos, como porcentaje del valor de la producción total.

Cuadro 4: Transferencias a los Productores de Contribuyentes como porcentaje del valor de Producción

\section{Argentina Brasil Colombia Costa Rica Honduras México}

Aceite de Palma

Algodón

Arroz

Azúcar Refinada

Café

Carne Vacuna

Huevo

0.05

Leche

Maíz

Piña

Plátano
7.9

3.3

6.3

4.8

8.8

0.7

0.05

0.1
0.4

0.4
0.3

0.2

0.3

0.2

Nota: Argentina, Brasil, Colombia, México, datos promedio para periodo 2015-2019. Honduras, datos 2015-2017.

Fuente: autores con datos de Agrimonitor.

Lo que resalta es el apoyo presupuestario al azúcar en varios países. Esto es separado del apoyo generado por la protección comercial, que será analizada más adelante. Este producto puede estar siendo subsidiado por motivos diferentes de los nutricionales, como su uso para etanol, o por ser una actividad con una participación no trivial de pequeños productores. 


\section{H. IMPUESTOS O SUBSIDIOS RELACIONADOS CON EL TRANSPORTE O LA VENTA MINORISTA DE PRODUCTOS ALIMENTICIOS SALUDABLES O NO SALUDABLES.}

Esta es una categoría de intervenciones muy amplia conceptualmente, pero poco aplicada en la práctica. No parece haber impuestos o subsidios relacionados con los aspectos de comercio o transporte en razón de ser alimentos saludables. Pero hay algunas intervenciones con ciertas implicaciones para las dietas.

En Honduras existe una Ley de Incentivo al Turismo (LIT) de 1999 que establece, entre otros beneficios, la exoneración de impuestos durante 10 años a partir de su creación, a empresas o establecimientos de diferente índole, incluyendo entre éstas a las que venden comidas rápidas. Las exoneraciones fiscales llegan hasta 15 años para inversiones turísticas y las empresas de comida rápida se consideran inversiones turísticas. La lista de productos exentos de pagar el impuesto de IVA llega a 180 bienes, aunque pocos de ellos pueden considerarse como necesidades de consumo básicos por parte de los sectores más desprotegidos o como alimentos nutritivos. (Cetrangolo y Gómez Sabaini 2006). Según la guía del exportador del USDA, Honduras tiene la mayor cantidad de franquicias de comida rápida de Centroamérica. Se ha estimado que las exoneraciones impositivas de todo tipo ascienden a un seis por ciento del total del PIB (Diario Confidencial Honduras, 18 julio 2018).

Colombia tiene un impuesto del $8 \%$ sobre el consumo en la venta de alimentos y bebidas en restaurantes, cafeterías, autoservicios, heladerías, fruterías, pastelerías y panaderías para consumo en el local, para llevar o entregar; servicios de alimentos bajo contrato, y el servicio de alimentos y bebidas alcohólicas para consumo en bares, tabernas y discotecas. Desde 2020, los restaurantes que operan bajo contratos de franquicia serán responsables del IVA y ya no estarán sujetos al impuesto al consumo (Societe Generale, 2020).

Varios países tienen distintas formas de subsidios de los combustibles (México, ${ }^{26}$ Chile ${ }^{27}$ ) y/o se aplican impuestos, como el IVA al transporte (Costa Rica ${ }^{28}$ ), pero son generales y no están relacionados con el tipo de producto transportado.

En el caso de Brasil hay una "Prima para el transporte de productos agrícolas" (VEP en portugués) que se lanzó en 2002. Es una prima que se ofrece en una subasta pública a los compradores (generalmente industria de alimento para animales, criadores de aves de corral, ganado y cerdos) de productos de existencias reguladoras del gobierno almacenadas en una región determinada. Los compradores pagan el precio mínimo establecido por el Gobierno. A su vez, como incentivo para estimular la compra del producto de un stock público almacenado en una localidad y usarlo en una región específica con

\footnotetext{
${ }^{26}$ Desde 2012 comenzó una reducción gradual a los subsidios a combustibles fósiles. Reducción del 20\% de los impuestos sobre la gasolina y el diésel debido al aumento de los precios. Impuesto a la emisión de carbono en los servicios de transporte (OECD, 2017b)

${ }^{27}$ Reintegro parcial del impuesto al diésel en el caso de transporte carga, en 2019 se aprobó una prorroga del subsidio hasta 2022. (Congreso Nacional de Chile, 2019; Mundo Marítimo, 2020)

${ }^{28}$ Luego de una reforma impositiva en 2019, el IVA tiene una tasa del 13\% sobre el transporte terrestre.

(EY and Deloitte Costa Rica- VAT Reform)
} 
escasez de oferta, el Gobierno paga una prima que corresponde aproximadamente a la diferencia entre el precio mínimo y el precio de mercado. Por lo tanto, a través de este instrumento, el Gobierno complementa el suministro de productos en regiones con déficit haciendo uso de sus existencias y pagando una prima que cubre el costo de transporte a un lugar específico y hace que la compra del producto sea atractiva para el comprador.

Ese país también tiene el Impuesto a la Circulación de Mercaderías y Servicios (ICMS), que es un impuesto estadual que se cobra en las diferentes fases de circulación de la mercancía, desde su producción hasta su venta al consumidor final. También se aplica a restaurants y bares y cualquier lugar donde se sirvan alimentos y bebidas (Santana y Nascimento, 2012; FAO, 2014).

Argentina ofreció durante algún tiempo un subsidio al costo de transporte de granos a los productores de la zona "extra pampeana", argumentando el alto costo de transporte que enfrentaban los agricultores en estos lugares. ${ }^{29}$

\section{MEDIDAS DE COMERCIO INTERNACIONAL}

Las políticas de comercio internacional están entre las medidas impositivas más importantes en relación con productos agro- alimentarios. En los Gráficos siguientes se muestra primero el impacto de un impuesto a un producto que se importa, y luego un impuesto a un producto que se exporta.

\section{Gráfico 4: Impuestos a las Importaciones}

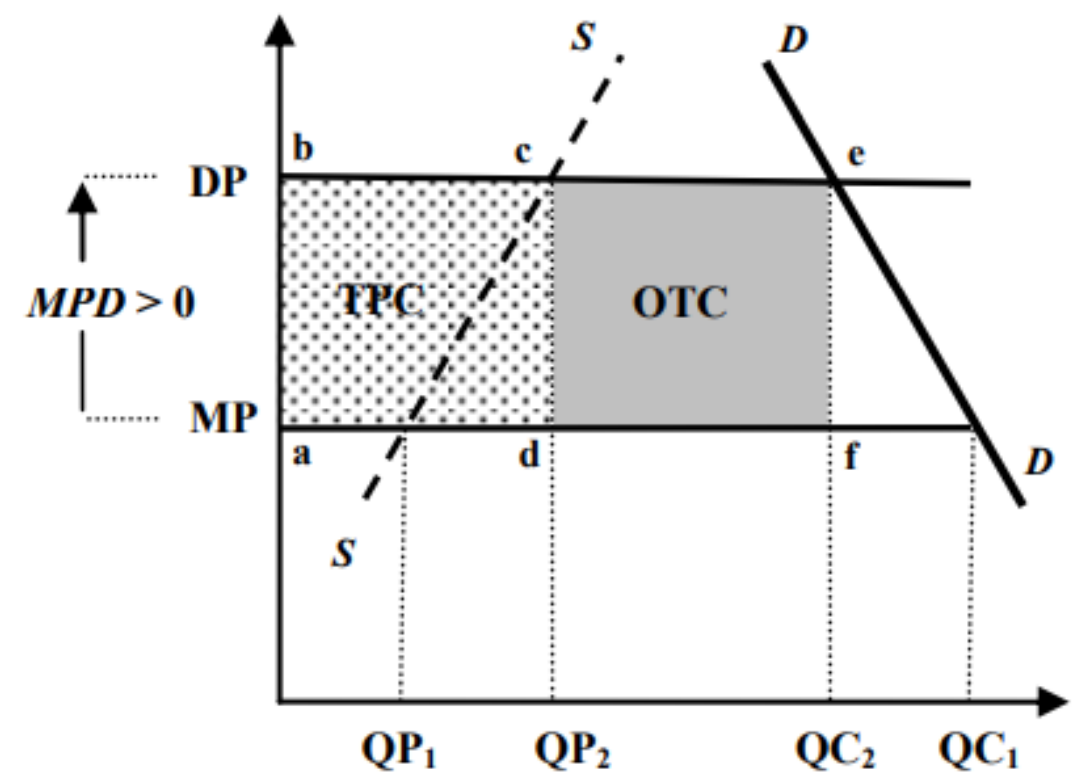

Fuente: OECD, 2016

\footnotetext{
${ }^{29}$ Canadá tuvo que eliminar un subsidio similar para zonas alejadas por ser considerado en violación de los acuerdos de la OMC.
} 
En este ejemplo, si el país usa el precio mundial (MP), entonces la producción es QP1 y el consumo es QC1. Por ende está importando la diferencia entre QC1 y QP1 (es decir, importaciones = QC1-QP1). Si se coloca un impuesto equivalente a la distancia "b" menos "a," esto hace subir el precio interno de MP hasta DP. Entonces hay más producción nacional, que llega a QP2, pero también hay menos consumo que antes, QC2, porque el precio interno subió. Ahora la cantidad producida cuesta más, y el consumidor paga el exceso marcado como TPC, que lo recibe el productor (TPC o transferencias al productor del consumidor), y una parte que recibe el gobierno (la zona OTC) como resultado de los impuestos de exportación sobre la parte que ahora se importa (QC2 menos QP2).

Si en lugar de un impuesto se usa una cuota para bajar las importaciones y aumentar la cantidad producida internamente, el precio interno también sube y el consumo cae; la única diferencia es quien recibe el valor de la zona OTC, lo que va a depender de la manera en que se otorga la cuota a los importadores).

Si en lugar de un producto de importación se tratara uno de exportación, el gráfico cambia como se muestra enseguida.

Gráfico 5: Impuesto a las Exportaciones

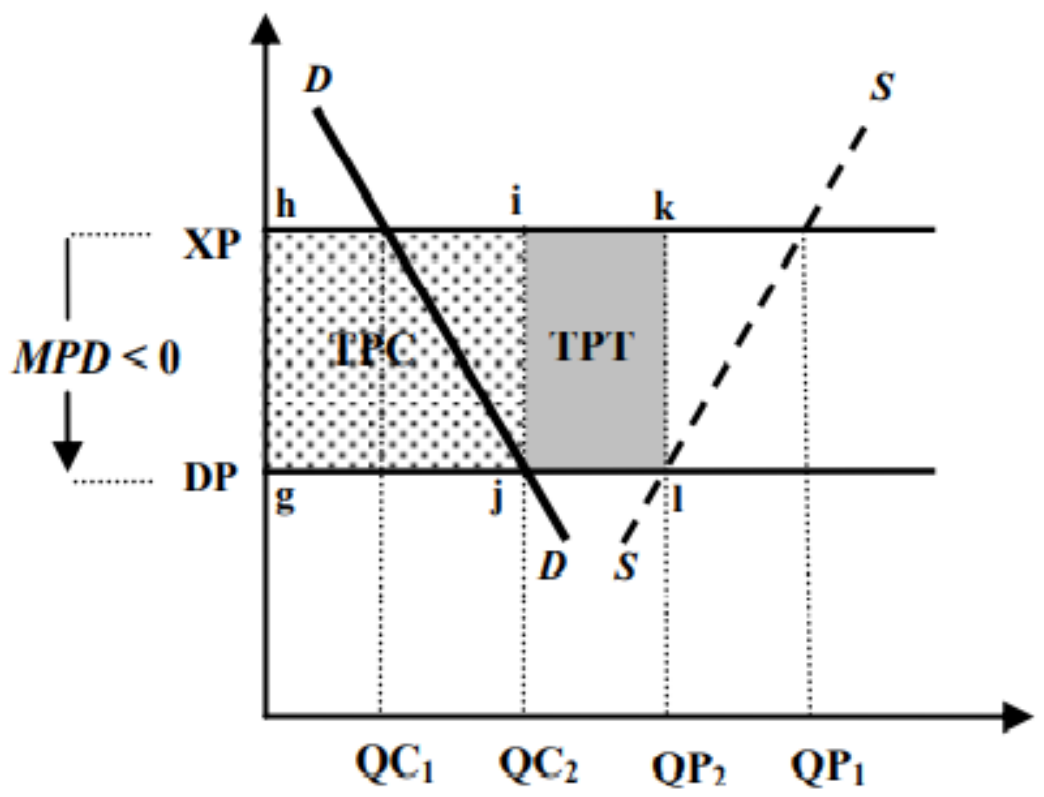

Fuente: OECD, 2016

Ahora el precio mundial es XP, y a ese precio, la producción es QP1 y el consumo es QC1, y la diferencia (QP1 - QC1), se exporta. Si se impone un impuesto a las exportaciones (equivalente a la distancia "h" menos "g"), el precio interno baja a DP, el consumo se incrementa a QC2, pero la cantidad producida baja a QP2 y las exportaciones son mucho menores (QP2-QC2).

Una parte de la diferencia en valores totales la recibe el gobierno (zona TPT), pero la otra parte (zona TPC) es un transferencia de los productores a los consumidores. La transferencia total desde los productores hacia consumidores y gobierno está representada por el área ghkl. 
Si en lugar de un impuesto se impusiera una prohibición de exportar, el gráfico sería igual, con un precio interno más bajo, más consumo doméstico, y menos exportaciones; la única diferencia es que ahora el gobierno no recibe la cantidad marcada TPT, sino que, en principio, la recibe el productor o quien haya recibido la cuota de exportación por parte del gobierno.

El punto a subrayar es que estas medidas cambian la producción y el consumo a la vez, por lo cual, por ejemplo, si se pone un impuesto a las importaciones de frutas y hortalizas para que haya más producción nacional, esto a la vez sube el precio interno, lo que desalienta el consumo.

Algunos ejemplos se discuten a continuación.

Por ejemplo, México subió los aranceles a la importación de maíz, sorgo, limones y tomates en 2013, y los de arroz en 2015, para alentar la producción nacional (FAO, 2016).

Costa Rica aplica impuestos de importación bastante altos a una serie de productos agropecuarios, tales como 151\% para las aves de corral; $66 \%$ para productos lácteos; $46 \%$ para carne de cerdo y azúcar y $36 \%$ para arroz, aunque las importaciones del Mercado Común Centroamericano (CACM) (excluido Panamá) ingresan a Costa Rica libres de impuestos, con excepción del azúcar y el café.

Jamaica tienen altos impuestos a las importaciones de carne y aves, frutas y verduras, y productos pesqueros, lo que sube le precio interno de productos alimenticios considerados saludables, pero también los aplica a grasas y aceites, y azúcar, que tienen condiciones nutricionales más controversiales (Del Mar Polo, et al., 2014; WTO, 2017).

Otro mecanismo con impactos en los precios internos de producción y consumo es la definición de pre-

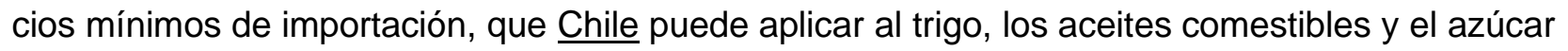
(ISPAF, 2020; WTO, 2006).

Las bandas de precios ${ }^{30}$ también afectan los precios internos. Colombia usa ese mecanismo en varios productos (arroz, cebada, maíz amarillo, maíz blanco, trigo de soja, aceite de soja sin refinar, aceite de palma sin refinar, azúcar sin refinar, azúcar refinada, leche, cortes de pollo y carne de cerdo) (OECD, 2020).

Un ejemplo de cuotas de importación para reducir lo que se compra en los mercados internacionales es Honduras, que tiene ese sistema para arroz y maíz. Aunque, dentro del acuerdo de libre comercio CAFTA-DR con Estados Unidos, las cuotas y las tarifas de importación irán disminuyendo (ITA, 2019). El país desde 2016 ha restringido las importaciones de leche y carne provenientes de Nicaragua mediante barreras no arancelarias, relacionadas con temas sanitarios (USAID, 2015).

Pasando a las exportaciones, el caso más notorio es Argentina, que en diferentes momentos ha usado impuestos a las exportaciones y también restricciones cuantitativas (cuotas de exportación), para diferentes productos como soja, trigo, girasol, maíz, leche, carne de res, arroz, frutas, hortalizas, y miel. ${ }^{31}$

Usando la metodología de la OECD, el BID calcula diferentes indicadores que cuantifican esas transferencias. El coeficiente de protección nominal del consumidor (NPC en inglés) sirve de aproximación para determinar si el consumidor de productos agropecuarios está pagando impuestos o recibiendo

\footnotetext{
${ }^{30}$ El sistema establece el precio mínimo (banda inferior) y un precio máximo (banda superior). Cuando el precio internacional está por debajo de la banda inferior, se impone un arancel de importación adicional; y cuando el precio internacional excede la banda superior, se otorga una reducción arancelaria. Este tipo mecanismo ha sido criticado en la OMC.

${ }^{31}$ https://www.oecd.org/officialdocuments/publicdisplaydocumentpdf/?cote=TAD/CA(2018)9/FINAL\&docLanguage=En; http://www.siepweb.it/siep/images/joomd/1401048793587.pdf
} 
subsidios en ese consumo en razón de políticas de comercio internacional. EI NPC estima la brecha entre el precio de consumo y el precio de frontera (medidos de manera equivalente). El gráfico siguiente muestra la estimación del NPC para todos los productos incluidos en el análisis de cada país entre 2015-201932 (que son diferentes entre sí debido a la estructura de producción y consumo de cada uno de ellos).

\section{Gráfico 6: Coeficiente de Protección Nominal}

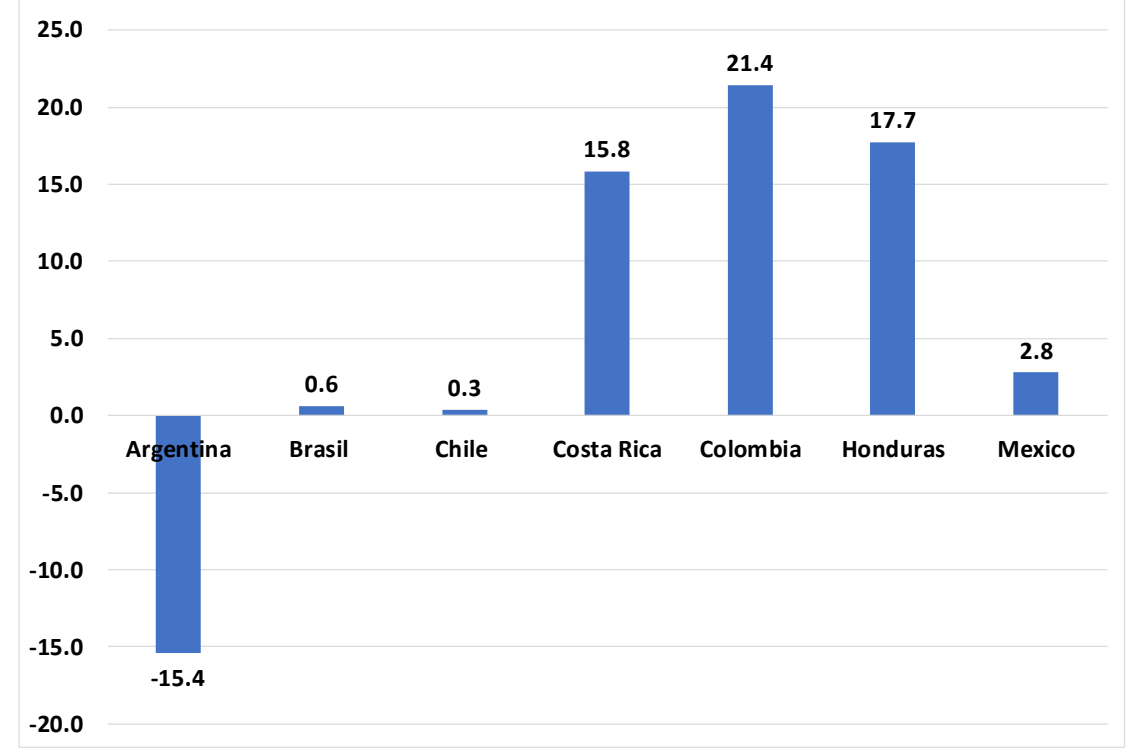

Fuente: autores con datos de Agrimonitor

En el agregado, los consumidores de Colombia, Costa Rica y Honduras pagan entre un $16 \%$ y un $21 \%$ más por los productos agropecuarios por las medidas de comercio internacional; los de México menos del 3\%; en el caso de Brasil y Chile están en línea con los precios internacionales; y los consumidores de Argentina pagan un 15\% menos.

Este número agregado no dice nada acerca de la calidad nutricional de los productos que pueden estar pagando más por los impuestos a las importaciones, o menos debido a los impuestos a las exportaciones.

Los gráficos siguientes muestran el desagregado por productos en varios de los países considerados que tienen mayores niveles de transferencias desde o hacia los productores o consumidores.

\footnotetext{
${ }^{32}$ En el caso de Honduras es el coeficiente nominal de asistencia (que es diferente del coeficiente de protección nominal del consumidor para el cual Honduras no tenía estimaciones en la base de datos) y es entre 2013-2017.
} 


\section{Gráfico 7: Colombia}

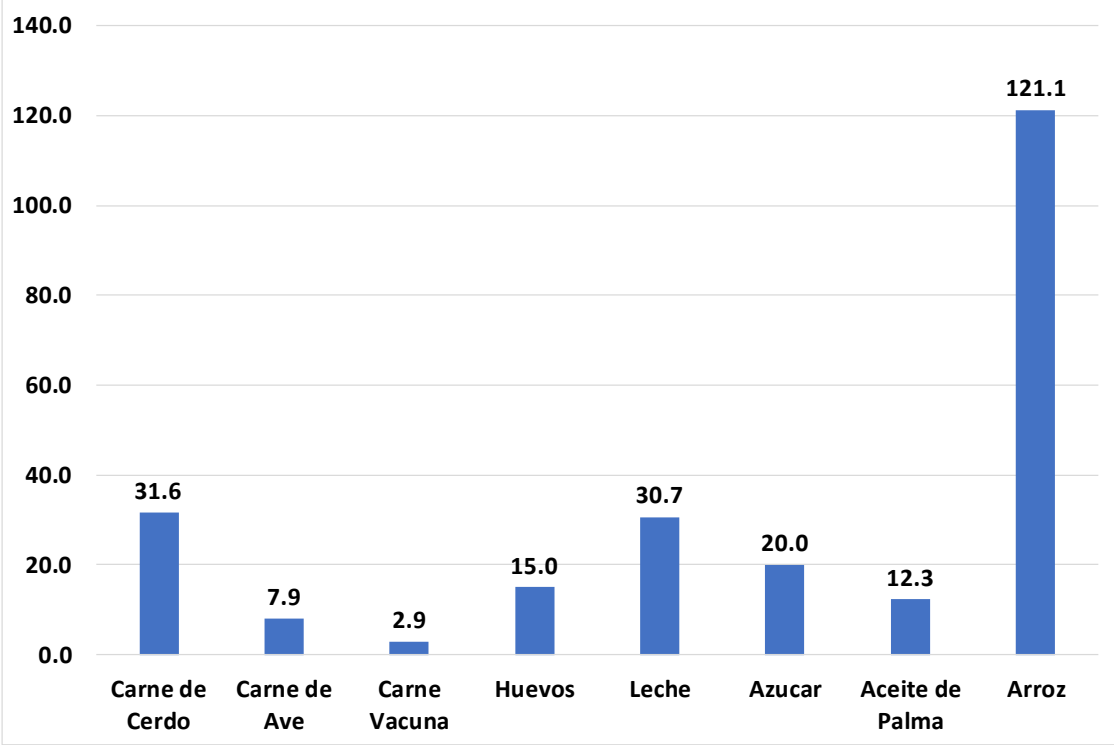

Fuente: autores con datos de Agrimonitor

\section{Gráfico 8: Argentina}

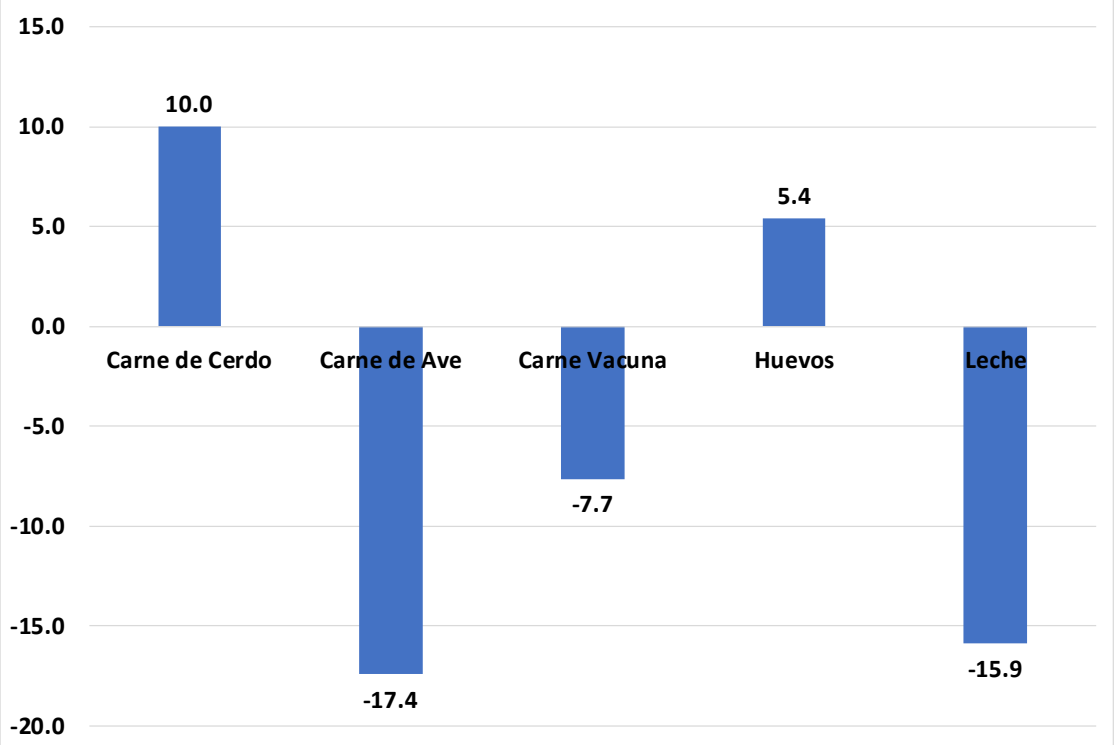

Fuente: autores con datos de Agrimonitor 
Gráfico 9: Honduras

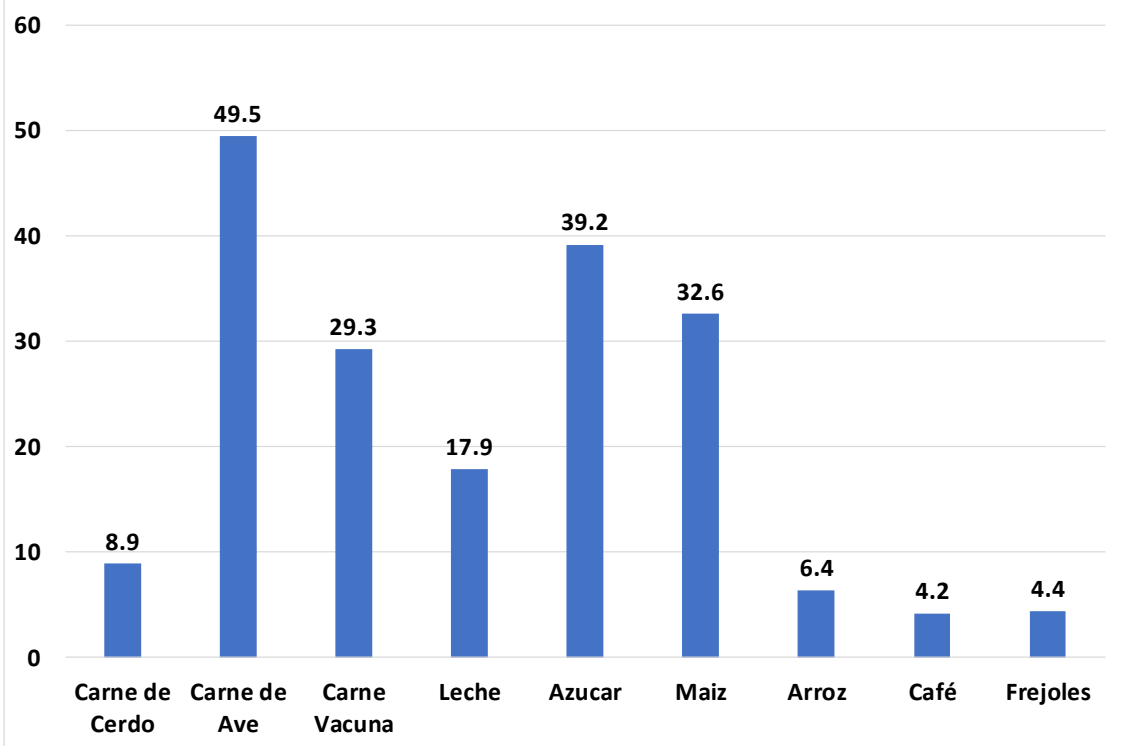

Fuente: autores con datos de Agrimonitor

Gráfico 10: Costa Rica

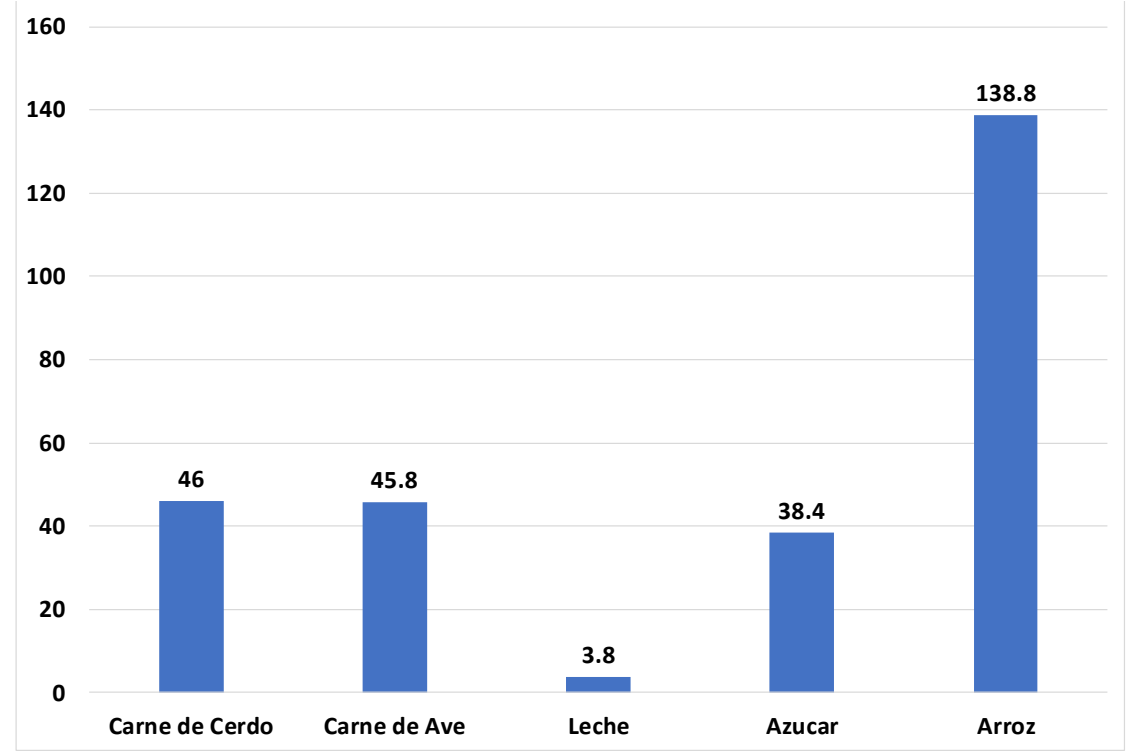

Fuente: autores con datos de Agrimonitor 


\section{Gráfico 11: Jamaica}

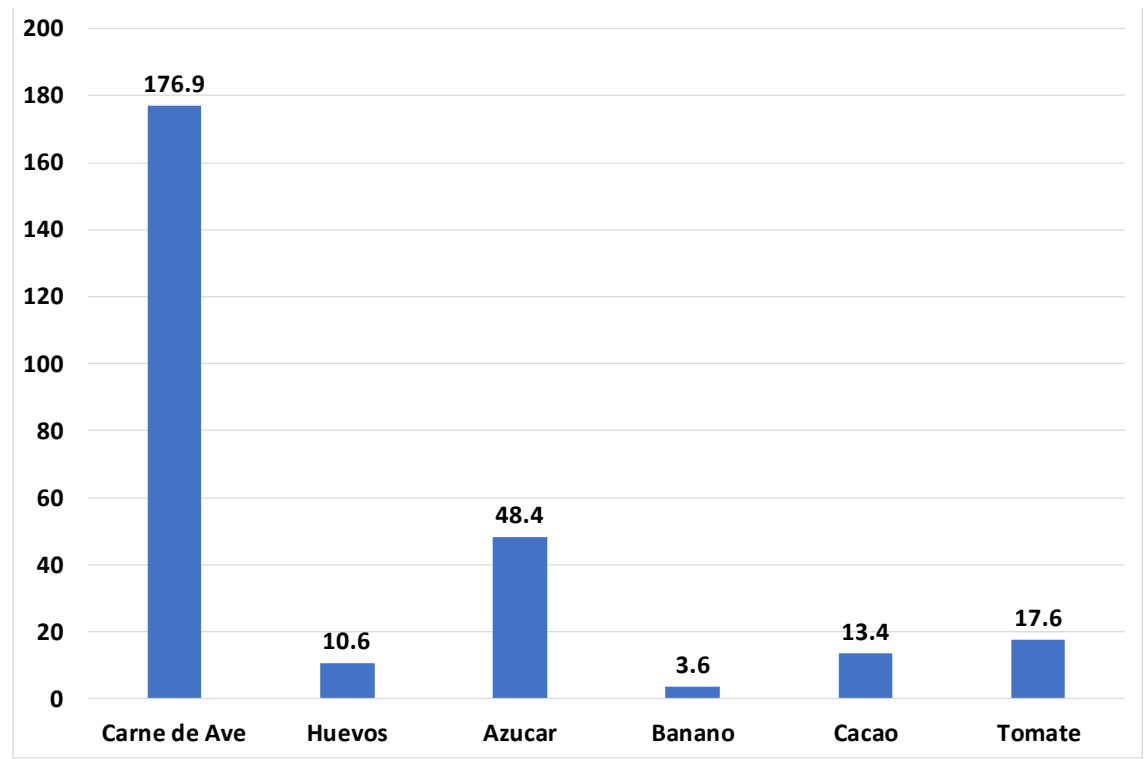

Fuente: autores con datos de Agrimonitor

En Argentina, las políticas de comercio internacional reducen los precios de toda una variedad de productos animales necesarios para la nutrición. Por otra parte, los otros países suben los precios de una variedad de productos proteínicos, y en el caso de Colombia y Costa Rica, también hacen más caros productos básicos para la energía como el arroz. En la dirección opuesta, el azúcar tiene precios más elevados que el equivalente a nivel mundial. Debe notarse que el nivel implícito de impuestos (20\% en Colombia, $38.4 \%$ en Costa Rica, $39.2 \%$ en Honduras, y $48.4 \%$ en Jamaica) son mucho más altos que los impuestos sobre consumo de productos con azúcar. Este también es el caso de México, cuyo cuadro no se muestra porque tiene solamente azúcar, donde el impuesto implícito llega al 46.3\%. Como se mencionó antes, el azúcar puede estar protegido (y subsidiado por los contribuyentes como se vio en otra sección) por razones que no tienen que ver con los aspectos nutricionales, como ser la producción de biocombustibles o la presencia de pequeños productores.

Un debate relacionado es el del impacto del comercio internacional sobre las dietas saludables o no saludables. Como se discute con mayor detalle en Díaz-Bonilla (2015), muchos análisis no distinguen entre tres definiciones: "comercio" como el intercambio físico y económico de bienes y servicios; "políticas comerciales", como las intervenciones de los gobiernos en esos flujos económicos y físicos cuando traspasan las fronteras nacionales; y "políticas relacionadas con el comercio de la OMC", como un conjunto más amplio de políticas incluidas en los acuerdos de la OMC (como medidas sanitarias y fitosanitarias, barreras técnicas al comercio, propiedad intelectual y similares). Los estudios sobre "comercio" y obesidad se han centrado en diferentes aspectos de esas tres definiciones, con una variedad de resultados empíricos (una discusión de más detalle está en Díaz-Bonilla, 2015). El comercio internacional ha llevado tanto a una mayor diversidad en la dieta con menores precios (especialmente la expansión de frutas y hortalizas), así como a un mayor comercio de productos procesados y de bebidas azucaradas. Algunos análisis han sugerido la necesidad de imponer impuestos a las importaciones a productos no saludables. Sin embargo, el poner esas barreras, si no se desalienta el consumo in- 
terno, puede fomentar la producción local de esos productos. Mucho más adecuado desde la perspectiva de bajar su uso es aplicar un impuesto al consumo, lo que cubre tanto los productos importados como los domésticos, y además es compatible con los acuerdos de la OMC.

Otras críticas se relacionan con el uso que han hecho algunas empresas del Tratado de Barreras Técnicas del Comercio de la OMC, para frenar regulaciones como etiquetado y aspectos relacionados. Esto ha llevado a críticas del marco legal de la OMC. Sin embargo, esto es una interpretación errónea de dicho tratado, en parte generado por la manera en que algunas empresas lo han querido invocar para frenar regulaciones de salud: los países tienen derecho a los estándares que consideren necesarios para diferentes objetivos societarios, incluyendo obviamente los aspectos de salud pública. El requisito central es que esas regulaciones se apliquen uniformemente a los productos nacionales y a los productos importados.

\section{J. CONTROLES DE PRECIOS}

Otras medidas que cambian los precios de productos alimenticios a nivel del consumidor y del productor son los controles de precios.

Por ejemplo, en el caso de Honduras, a fines de 2015 el gobierno promovió un acuerdo de estabilidad de precios en veinte productos básicos: cebollas, tomates, papas, zanahorias, calabaza, café, arroz, frijoles, maíz, trigo y harina de maíz, mantequilla, leche, azúcar y hojas de plátano, y sus derivados. ${ }^{33}$

Argentina ha venido aplicado un programa llamado de "Precios Cuidados," que es una lista de precios de referencia que los consumidores pueden comparar con los precios minoristas efectivos en productos como lácteos, pan, algunos cortes de carne, algunos vegetales, bebidas alcohólicas y no alcohólicas, y otros, como productos de limpieza. Los clientes pueden informar a la agencia gubernamental si los productos no están disponibles o son más caros que los precios de referencia. Sin embargo, no tienen necesariamente un enfoque de dietas saludables, y más bien se orientan a todos los productos alimentarios de consumo masivo, lo que abarata relativamente a todos los productos sin distinción de calidad nutricional.

Pero no son medidas fiscales, a menos que a raíz de los controles se decida compensar a los productores (como se comentó antes en el caso de la leche en Argentina).

\footnotetext{
${ }^{33}$ Búsqueda en centralamericadata.com. Accedido, 20 de octubre de 2020. https://www.centralamericadata.com/en/search?q1=content en 1 \% $\% 3 \mathrm{~A} \% 22 \mathrm{Food}+$ basket $\% 22 \& q 2=$ matters InCountry en $1 \mathrm{l} \% 3 \mathrm{~A} \% 22$ Honduras $\% 22$
} 


\section{K. CONCLUSIONES}

En este documento se han analizado diferentes impuestos y otros aspectos fiscales que afectan los precios de productores y consumidores y, en general, el acceso económico a dietas saludables.

No parecen haber impuestos internos a la producción de productos no saludables. Esto es diferente de los impuestos de comercio internacional, que se mencionan más adelante.

Por otra parte, sí hay varios ejemplos de impuestos internos al consumo de alimentos no saludables; los casos más notables son los de México y Chile. En particular en el caso de México se aplican a comidas no necesarias con alto contenido calórico (comida "chatarra") y a bebidas azúcar añadida. Las evaluaciones muestran que esos impuestos tienen impacto, especialmente a partir de un cierto nivel mínimo de la tasa, y que afectan más a los niveles de menores ingresos. Sin embargo, dado que estos grupos también sufren más de enfermedades no transmisibles, el efecto total puede ser considerado progresivo.

Las evaluaciones también muestran que hay toda una serie de sustituciones en el consumo que deben ser considerados. Por ejemplo, el impacto del impuesto de Chile con su característica de tener diferentes valores según los niveles de azúcar parece que no sería tan importante en los productos gravados (sería muy pequeño el valor del impuesto), pero a la vez ha llevado a aumentos de precios en otros productos no alcanzados por los mismos, lo que generó una mayor reducción de consumo de calorías que los relacionados con los productos objeto de los impuestos.

La Organización Mundial de la Salud (Thow et al. 2010) ha recomendado que el impuesto al consumo de bebidas azucaradas y comida de alto contenido calórico supere la alícuota del $20 \%$. Sin embargo, ningún país de la Región lo ha aplicado a nivel del consumo. Se ha argumentado que esos impuestos llevarían a la reducción del consumo de productos nocivos para la salud con el consiguiente ahorro en el gasto de salud pública y mejora de la productividad de la población. El problema de la obesidad es aún más acuciante en las próximas décadas cuando gran parte de los niños (INSP - UNICEF, 2016) de hoy pasen a formar parte de la masa laboral de estos países. Es importante mantener la discusión de estos temas dentro del debate público, porque si bien los beneficios no se sienten en el corto plazo (los siguientes cuatro años para los políticos y representantes legislativos) son muy relevantes en el largo plazo pudiendo afectar el potencial de crecimiento de la Región.

En lo que hace a los subsidios a la producción hay pocos ejemplos de casos en los que se basen en aspectos nutricionales y más bien se refieren a temas como el apoyo a pequeños productores o para mejorar la competitividad internacional. Un caso especial puede ser el de Cundinamarca en Colombia donde se está financiando la producción de frutas y hortalizas. Habría que ampliar programas específicos de apoyo a productos nutricionales como frutas, hortalizas y nueces, pero no mediante subsidios de precios sino inversiones en investigación, extensión, infraestructura y otras políticas de apoyo como crédito y seguros. También se puede resaltar el apoyo a pequeños productores a través de programas de provisión de frutas y verduras a escuelas y otras instituciones públicas, como es el caso Brasil y en menor medida Honduras.

Las políticas de impuestos al comercio internacional tienen el doble impacto sobre consumidores y productores. Los impuestos a las importaciones aumentan el precio del producto local lo cual lleva a más 
producción, pero también incrementa el costo para los consumidores. En el caso de Argentina los impuestos a las exportaciones de productos de la ganadería, así como a productos de alimentación animal bajan el costo para los consumidores de estos productos. Pero en los otros países analizados, las políticas de protección de productos de la ganadería, con el objetivo de incrementar la producción, terminan subiendo el precio para los consumidores de una variedad de productos animales necesarios para una dieta saludable. Este castigo al consumo también aparece en algunos productos importantes por su aporte de energía como el arroz.

Se mencionó también la importante protección al azúcar en varios países, lo que favorece la producción, pero a la vez castiga el consumo. Como se mencionó, los impuestos de comercio internacional parecen ser más altos que los impuestos internos aplicados en países como México y Chile a productos con alto contenido de azúcar.

En relación al comercio internacional de productos no saludables (altamente procesados, bebidas con alto contenido de azúcar) se argumentó que los impuestos a las importaciones no son muy útiles, porque alientan la producción local de esos productos. Más relevante sería usar impuestos al consumo o regulaciones que apliquen igual para productos nacionales e importados, lo que además es consistente con la OMC.

Hacen falta más estudios de evaluación para poder entender los efectos combinados. Las simulaciones mencionadas en el caso de Chile muestran la importancia de considerar de manera integrada tanto los impuestos a los productos no saludables como los subsidios a los productos saludables. Al evaluar el resultado integral de impuestos y subsidios se debería incluir el impacto en el bienestar social mediante reducción del gasto en salud pública, extensión de la esperanza de vida de las personas, y mejoras en la productividad de la mano de obra. Esto permitiría comprender el alcance completo de estas medidas.

También hay que combinar las medidas por el lado del consumo con programas desde la oferta que eleven el apoyo a la producción eficiente y competitiva de productos de alta calidad nutricional. En este sentido, es importante reconocer, como ya se señaló, el doble efecto de las políticas de comercio internacional, que pueden llevar al aumento del precio interno de productos saludables con el argumento de incrementar la producción nacional. 


\section{SOBRE LOS AUTORES}

\section{Eugenio Díaz-Bonilla lidera el Programa de América Latina y el Caribe del IFPRI}

Miriam Centurión es consultora del IFPRI, ex Consejera del Directorio Ejecutivo del BID

Florencia Paz es Analista de Investigación en la División de Mercados, Comercio e Instituciones y del Programa para Latinoamérica y el Caribe del IFPRI.

\section{BIBLIOGRAFÍA}

Aburto, T.C., Pedraza, L.S., Sánchez-Pimienta, T.G., Batis, C. and Rivera, J.A., (2016). Discretionary foods have a high contribution and fruit, vegetables, and legumes have a low contribution to the total energy intake of the Mexican population. The Journal of nutrition, 146(9), pp.1881S-1887S. https://academic.oup.com/jn/article/146/9/1881S/4584715

Alvarez-Sánchez C, Contento I, Jiménez-Aguilar A, Koch P, Gray HL, Guerra LA, et al. (2018) Does the Mexican sugar-sweetened beverage tax have a signaling effect? ENSANUT 2016. PLoS ONE 13(8): e0199337. https://doi.org/10.1371/journal.pone.0199337.

Batis C et al. (2016) First-Year Evaluation of Mexico's Tax on Nonessential Energy-Dense Foods: An Observational Study. PloS Medicine 13(7): e1002057 https://pubmed.ncbi.nlm.nih.gov/27379797/

Batis, C., Pedraza, L.S., Sánchez-Pimienta, T.G., Aburto, T.C. and Rivera-Dommarco, J.A., (2017). Energy, added sugar, and saturated fat contributions of taxed beverages and foods in Mexico. salud pública de méxico, 59, pp.512-517.

Bergallo, P., Castagnari, V., Fernández, A. and Mejía, R., (2018). Regulatory initiatives to reduce sugar-sweetened beverages (SSBs) in Latin America. PloS one, 13(10), p.e0205694. https://www.ncbi.nlm.nih.gov/pmc/articles/PMC6195269/

Biermayr-Jenzano, Patricia (2020). Medidas de protección social para la adopción de dietas sanas y accesibles en América Latina y el Caribe: Una revisión de la literatura. LAC Working Paper 10. Washington, DC: International Food Policy Research Institute (IFPRI). https://doi.org/10.2499/p15738coll2.134027.

Caro, J.; Corvalán, C.; Reyes, M.; Silva, A.; Popkin, B.; Taillie, L.. (2018). Chile's 2014 sugar-sweetened beverage tax and changes in prices and purchases of sugar-sweetened beverages: An observational study in an urban environment https://journals.plos.org/plosmedicine/article?id=10.1371/journal.pmed.1002597

Caro, J.; Valizadeh, P.; Correa, A.; Silva, A.; Shu Wen Ng (2020). Combined fiscal policies to promote healthier diets: Effects on purchases and consumer welfare https://journals.plos.org/plosone/article?id=10.1371/journal.pone.0226731

Cetrángolo, O. and Gomez Sabaini, J.C., (2006). Tributación en América Latina: en busca de una nueva agenda de reformas. CEPAL. http://infofiscal.conare.ac.cr/images/docs/citada/Cetrangolo_O._Y_Gomez_C._2006_-_Tributacion_en_AL.pdf

Colchero $\mathrm{M}$ et al.(2016). Beverage purchases from stores in Mexico under the excise tax on sugar sweetened beverages: observational study. British Medical Journal, 352, h6704.

Colchero, M. A., Rivera-Dommarco, J., Popkin, B. M., \& Ng, S. W. (2017). In Mexico, Evidence Of Sustained Consumer Response Two Years After Implementing A Sugar-Sweetened Beverage Tax. Health affairs (Project Hope), 36(3), 564-571. https://doi.org/10.1377/hlthaff.2016.1231

Colchero, M.Arantxa; Rivera, Juan; Popkin Barry; Shu Wen Ng. (2018) Sustained consumer response: evidence from twoyears after implementing the sugar sweetened beverage tax in Mexico. (https://www.ncbi.nlm.nih.gov/pmc/articles/PMC5442881/)

Confidencial Honduras,(2018). Por perdonar impuestos a la gran empresa, Honduras no recibirá 36 mil millones de lempiras. 18 julio 2018. Accedido 20 oct. 2020. https://confidencialhn.com/por-perdonar-impuestos-a-comidas-rapidas-y-multinacionales-honduras-dejara-de-percibir-36-mil-millones-de-lempiras/

Congreso Nacional de Chile, (2019). Historia de la Ley № 21.139. https://www.bcn.cl/historiadelaley/historia-de-la-ley/vistaexpandida/7622/

Del Mar Polo, M., Mullins, P., Santos, N., Selvaraju, R., Serova, E., Shik, O., Stevens, C. and Trapido, P.J., (2014). Jamaica: review of agricultural sector support and taxation. FAO Investment Centre. Country Highlights (FAO) eng no. 13. http://www.fao.org/3/i3552e/i3552e.pdf

Díaz-Bonilla, Eugenio. (2015). Lost in translation: the fractured conversation about trade and food security. Background paper prepared for The State of Agricultural Commodity Markets 2015-16. Rome, Italy: Food and Agricultural Organization of the United Nations (FAO). http://www.fao.org/3/a-i5219e.pdf 
Diaz-Bonilla, Eugenio; Rapallo, Ricardo; Intini, Joao; Paz, Flor; and Hernández, Yenory (2018). Foro sobre los sistemas alimentarios y la obesidad en América Latina y el Caribe. Washington, DC: International Food Policy Research Institute (IFPRI)

Diaz-Bonilla, Eugenio; Paz, Flor; and Biermayr-Jenzano, Patricia. (2020). Nutrition policies and interventions for overweight and obesity: A review of conceptual frameworks and classifications. LAC Working Paper 6. Washington, DC: International Food Policy Research Institute (IFPRI). https://doi.org/10.2499/p15738coll2.133584

ECLAC, (2017a). Brasil: Rede de Equipamentos Públicos de Alimentação. Plataforma de Seguridad Alimentaria y Nutricional. Accedido 20 Oct. $2020 \mathrm{https}: / /$ plataformacelac.org/programa/93

ECLAC, (2017b).Chile: Programa de Innovación en Alimentos + Saludables. Plataforma de Seguridad Alimentaria y Nutricional. Accedido 20 Oct. 2020 https://plataformacelac.org/programa/449

ECLAC, (2017c). Chile: Seguros para el AGRO. Plataforma de Seguridad Alimentaria y Nutricional. Accedido 20 Oct. 2020 https://plataformacelac.org/programa/460

Essman, M.; Popkin, B.; Corvalán, C.; Reyes, M.; and Taillie, L. (2018) Sugar-Sweetened Beverage Intake among Chilean Preschoolers and Adolescents in 2016: A Cross-Sectional Analysis https://www.ncbi.nlm.nih.gov/pmc/articles/PMC6265687/

FAO, (2001). Experiences in Targeting Nutrition Programmes. Annex in Targeting for Nutrition Improvement: Resources for Advancing Nutritional Well-Being. Rome. http://www.fao.org/3/y1329e/y1329e07.htm

FAO, (2014). Country Fact Sheet on Food and Agriculture Policy Trends: Brazil. Accedido 20 Oct. 2020 http://www.fao.org/3/i3759e/i3759e.pdf

FAO, (2016). Country Fact Sheet on Food and Agriculture Policy Trends: Mexico. Accedido 20 Oct. 2020 http://www.fao.org/3/a-i6006e.pdf

Gobierno de la República de Honduras, (2020). Merienda Escolar. Accedido 20 Oct. 2020. http://www.ceniss.gob.hn/sigeth/merienda.html

Hernandez, M.; Batis, C.; Rivera, J.; Colchero, M. (2018). Reduction in purchases of energy-dense nutrient-poor foods in Mexico associated with the introduction of a tax in 2014 (https://www.ncbi.nlm.nih.gov/pmc/articles/PMC6322966/)

Hernandez Ore, Marco Antonio, Liliana D. Sousa, and J. Humberto Lopez. (2016). "Honduras: Unlocking Economic Potential for Greater Opportunities." Systematic Country Diagnostic. World Bank, Washington, DC. License: Creative Commons Attribution CC BY 3.0 IGO http://documents1.worldbank.org/curated/en/519801468196163960/pdf/103239-v2-PUBP151906-Box394858B-PUBLIC-DOI-10-1596K8570-EPI-K8570.pdf

Instituto Nacional de Salud Pública (INSP) y UNICEF México. (2016). Encuesta Nacional de Niños, Niñas y Mujeres 2015 Encuesta de Indicadores Múltiples por Conglomerados 2015, Informe Final. Ciudad de México, México: Instituto Nacional de Salud Pública y UNICEF México. https://www.unicef.org/mexico/media/1001/file/UNICEF_ENIM2015.pdf

International Trade Administration (ITA) (2019). Honduras - Pricing. https://www.export.gov/apex/article2?id=Honduras-Pricing. Accedido 20 Oct. 2020.

Instituto Superior de Procedimientos Aduaneros y Fiscales (ISPAF), (2020). Aranceles e Impuestos en Chile. http://www.ispaf.institute/es/sud-america/tramites-aduaneros-en-chile/aranceles-e-impuestos-en-chile\#

Kahneman D, Tversky A. (1979) Prospect Theory: An Analysis of Decision under Risk. Econometrica. 1979;47(2):263-92.

Lema, D.; Gallacher, M.; Egas Yerovi, J.J.; and De Salvo C. P., (2018). Analysis of Agricultural Policies in Argentina 20072016. Monografía del BID ; 695. https://publications.iadb.org/publications/english/document/Analysis_of_Agricultural_Policies_in_Argentina_2007\%E2\%80\%932016_en_en.pdf

Ministerio de Educación Gobierno de Chile, (2020). Programa de Alimentación Escolar (PAE). Accedido 20 Oct. 2020. https://www.junaeb.cl/programa-de-alimentacion-escolar

Ministerio de Salud Gobierno de Chile, (2020). Programa Nacional de Alimentación Complementaria (PNAC). Accedido 20 oct. 2020. https://dipol.minsal.cl/departamentos-2/nutricion-y-alimentos/programas-alimentarios/pnac/

Mundo Marítimo, (2020). Chile: Revisión de exenciones tributarias podría reabrir debate sobre eliminación de beneficios al transporte de carga. 01 septiembre 2020. Accedido 20 oct. 2020. https://www.mundomaritimo.cl/noticias/chile-revision-deexenciones-tributarias-podria-reiniciar-discusion-sobre-la-eliminacion-de-beneficios-al-transporte-de-carga

Nakamura, R., Mirelman, A.J., Cuadrado, C., Silva-Illanes, N., Dunstan, J. and Suhrcke, M., (2018). Evaluating the 2014 sugar-sweetened beverage tax in Chile: an observational study in urban areas. PLoS medicine, 15(7), p.e1002596. https://journals.plos.org/plosmedicine/article?id=10.1371/journal.pmed.1002596\#abstract2

$\mathrm{Ng} \mathrm{S.W.} \mathrm{et} \mathrm{al.} \mathrm{(2018).} \mathrm{Did} \mathrm{high} \mathrm{sugar-sweetened} \mathrm{beverage} \mathrm{purchasers} \mathrm{respond} \mathrm{differently} \mathrm{to} \mathrm{the} \mathrm{excise} \mathrm{tax} \mathrm{on} \mathrm{sugar-sweet-}$ ened beverages in Mexico? Public Health Nutrition 22(4):1-7.xV

OECD, (2016). OECD'S Producer Support Estimate and Related Indicators of Agricultural Support. Concepts, Calculations, Interpretation and Use (The PSE Manual). Trade And Agriculture Directorate.

OECD, (2017a). Agricultural Policies in Costa Rica, OECD Food and Agricultural Reviews, OECD Publishing, Paris, https://doi.org/10.1787/9789264269125-en. 
OECD, (2017b). Mexico's efforts to phase out and rationalise its fossilfuel subsidies. https://www.oecd.org/fossil-fuels/MexicoPeer-Review.pdf

OECD, (2020). Agricultural Policy Monitoring and Evaluation. Accedido 20 Oct. 2020. http://www.oecd.org/agriculture/topics/agricultural-policy-monitoring-and-evaluation/

PAHO, (2015).Taxes on Sugar-sweetened Beverages as a Public Health Strategy: The Experience of Mexico. Mexico DF, Mexico. https://iris.PAHO.org/bitstream/handle/10665.2/18391/9789275118719_eng.pdf?sequence=1\&isAllowed=y

Piñeiro, Valeria; Diaz-Bonilla, Eugenio; Paz, Flor; and Allen, Summer L. (2019). Sugar taxes: An economy-wide assessment: The case of Guatemala. LAC Working Paper 3. Washington, DC: International Food Policy Research Institute (IFPRI). https://doi.org/10.2499/p15738coll2.133415

Presidencia Argentina, (2019). Impuesto al Valor Agregado, Decreto 567/2019. Boletín Oficial de la República Argentina. Accedido 20 Oct. 2020.https://www.boletinoficial.gob.ar/detalleAviso/primera/213586/20190816.

Presidência da República de Brasil, (2009). LEI № 11.947. Accedido 20 Oct. 2020. http://www.planalto.gov.br/ccivil_03/_Ato2007-2010/2009/Lei/L11947.htm

Presidency of the Republic of Brazil, (2018). Brazil to cut 144,000 tons of sugar from food and beverages. Accedido 20 Oct. 2020. http://www.brazil.gov.br/about-brazil/news/2018/11/brazil-to-cut-144-000-tons-of-sugar-from-food-and-beverages

Santana, C.A.M. and Nascimento, J.R., (2012). Public policies and agricultural investment in Brazil. Rome: FAO, Available online at: http://www. fao. org/fileadmin/templates/tci/pdf/InvestmentPolicy/Inv_in_Br_agriculture_-_20_08_2012. pdf.

Santarelli, M., Marques Vieira, L. and Constantine, J., (2018). Learning from Brazil's Food and Nutrition Security Policies. IDS, The Food Foundation. https://foodfoundation.org.uk/wp-content/uploads/2018/02/Learning-from-Brazilian-Food-and-Nutrition-Security-Policies_final_clean_rev_FF.pdf

Smit, E.; Snijders, R.; and van den Bos, A., (2014). Green Opportunities with an Orange Touch in Colombia: Business Leads in the Horticultural Sector Ideavelop \& Verbos Business Development. Netherlands Enterprise Agency. https://english.rvo.nl/sites/default/files/2015/03/Green\%20Opportunitie\%20with\%20an\%20Orange\%20Touch\%20in\%20Colombia\%202014.pdf

Societe Generale, (2020). Colombian Market: Consumption Taxes. Accedido 20 Oct. https://import-export.societegenerale.fr/en/country/colombia/market-taxes?accepter_cookies=oui

Taillie, L. S., Rivera, J. A., Popkin, B. M., \& Batis, C. (2017). Do high vs. low purchasers respond differently to a nonessential energy-dense food tax? Two-year evaluation of Mexico's 8\% nonessential food tax. https://doi.org/10.1016/j.ypmed.2017.07.009 https://www.ncbi.nlm.nih.gov/pmc/articles/PMC5732875/

Ter-Minassian, T., (2012). Reform priorities for sub-national revenues in Brazil. IDB Policy Brief No.IDB-PB-157. https://ewsdata.rightsindevelopment.org/files/documents/74/IADB-BR-L1374_UxhMymY.pdf

Thow, Anne Marie; Jan, Stephen; Leeder, Stephen; Swinburn, Boyd. (2010). The effect of fiscal policy on diet, obesity and chronic disease: A systematic review. Bulletin of the World Health Organization. 88. 609-14. 10.2471/BLT.09.070987.

USAID, (2015). A Report on Barriers to Competition in Food-Related Markets in El Salvador, Guatemala, and Honduras. https://www.antitrustinstitute.org/wp-content/uploads/2018/09/PA00KGS2.pdf

WTO, (2006). Perfiles Arancelarios en el Mundo. https://www.wto.org/spanish/tratop_s/tariffs_s/tariff_profiles_2006_s/chl_s.pdf

WTO, (2017). Trade Policy Review: Jamaica. https://www.wto.org/english/tratop_e/tpr_e/s359_e.pdf

Este documento de trabajo es parte de un proyecto más amplio sobre sistemas alimentarios y obesidad, en colaboración y financiamiento de FAO-LAC. No ha sido revisado por pares de forma independiente.

INTERNATIONAL FOOD POLICY RESEARCH INSTITUTE

A world free of hunger and malnutrition

IFPRI is a CGIAR Research Center

1201 Eye Street, NW, Washington, DC 20005 USA | T. +1-202-862-5600 | F. +1-202-862-5606 | Email: ifpri@cgiar.org | www.ifpri.org | www.ifpri.info 